\title{
How shifting investment towards low-carbon sectors impacts employment: three determinants under scrutiny
}

\author{
Quentin Perrier $^{\mathrm{a}, *}$, Philippe Quirion ${ }^{\mathrm{b}}$ \\ ${ }^{a}$ CIRED, 45 bis, avenue de la Belle Gabrielle, 94736 Nogent-sur-Marne Cedex, France \\ ${ }^{b}$ CIRED, CNRS, 45 bis, avenue de la Belle Gabrielle, 94736 Nogent-sur-Marne Cedex, France
}

\begin{abstract}
The threat of climate change requires redirecting investment towards low-carbon sectors, and this shift generates heated debates about its impact on employment. Many studies exist, most of which use CGE or Input-Output (IO) models. However, the economic mechanisms at play remain unclear. This paper disentangles the channels of job creation and studies to what extent the results of simpler IO models diverge from CGE results.

Using stylized models, we show that a shift in investment creates jobs in IO if it promotes sectors with a higher share of labour in value added, lower wages or a lower import rate. In CGE, the first two channels also yield job creation, but there is no positive impact of targeting low-imports sectors - unless these do not export. Then we undertake a numerical analysis of two policies: the installation of solar panels and weatherization in France. Both policies have a positive effect on employment, in both models, due to the high share of labour and low wages in these sectors. IO results provide a good approximation of CGE results for solar $(-14 \%$ to $+34 \%)$ and are slightly higher for weatherization $(+22 \%$ to $+87 \%)$.

Our findings challenge the idea that renewables boost employment by reducing imports, but they also suggest that a double dividend can be achieved by encouraging low-carbon labour-intensive sectors.
\end{abstract}

Keywords: Renewable energies; Investment; Employment; CGE; Input-output

JEL Classification: C67, C68, E24, Q42, Q43

\section{Highlights}

- We identify three channels of job creation when redirecting investments

- Encouraging labour-intensive or low-wage sectors creates employment in CGE and IO models

- Encouraging low-importing sectors generates a marked positive effect in IO, but little to no effect in CGE

- Numerically, investing in solar panels or weatherization creates jobs in both models.

*Corresponding author. Tel.: +33663246813

Email addresses: perrier@centre-cired.fr (Quentin Perrier), quirion@centre-cired.fr (Philippe Quirion) 


\section{Introduction}

Is it possible to reduce greenhouse gas emissions while creating jobs? Many countries today face the dual challenge of climate emergency and unemployment. The need to mitigate global warming is unanimously recognized by the international scientific com5 munity, but the current emission trajectories seem to commit us to a warming of around $3^{\circ} \mathrm{C}$. At the same time, the consequences of the economic crisis continue to be felt, with a high level of unemployment in the countries of Southern Europe.

A major challenge for a successful energy transition is to redirect investment towards low-carbon sectors. As early as Article 2, the Paris Agreement stresses the importance

10 of "making financial flows compatible with the path of low greenhouse gas emission and climate resilient development". Every year, nearly $\$ 1.8$ trillion is invested in energy. These flows must be diverted from fossil fuels and directed towards low-carbon sectors, in order to support the development of renewable energies and the improvement of energy efficiency.

15 Reorienting these massive flows involves transformations that raise hopes and fears about their impact on employment. In the current context of persistent unemployment, job creation has become a central argument in the public debate on energy transition. Renewable energies or the renovation of buildings are often defended for their potential to create "green jobs", due to more local, less capital intensive and more labour intensive

20 production. But similar arguments were also used by Donald Trump to leave the Paris Agreement, on the grounds of protecting jobs in the coal industry. ${ }^{1}$ Much more than a simple co-benefit or second dividend, the impact on employment has thus become a powerful lever for action on public climate policies.

Moreover, demonstrating the existence of an employment dividend would make it

25 possible to escape the "tragedy of the commons" that characterises climate change. Although the Paris Agreement has made countries' emission commitments more ambitious, international negotiations still stumble on some form of prisoner's dilemma: individually, each nation could try to free-ride as much as possible and let other countries bear the bulk of the climate burden. This partly explains why the sum of the Paris Agree-

30 ment's INDCs is far from achieving its overall objective of staying "well below $2^{\circ} \mathrm{C}^{\prime \prime} 2$ even though the IPCC Chair, Dr. Pachauri, considers that "the solutions are numerous and make it possible to pursue economic and human development. All we need is the will to change" 3 . The benefits in terms of employment can make it possible to get out of this opposition between economy and ecology, and thus accelerate the international response against global warming.

A stream of literature, known as the "double dividend", has sought to identify policies that jointly achieve an environmental benefit (the first dividend) and an economic benefit (the second dividend). If the economic criterion is more specifically that of employment, then we speak of "employment double dividend". Economists have promoted the use of taxes to correct externalities since the work of Pigou (1920), but the concept of "double

\footnotetext{
${ }^{1}$ In the speech explaining his exit from the Paris Agreement, Donald Trump emphasized the importance of coal-related jobs in the United States, using the word "job" eighteen times.

${ }^{2}$ According to the OECD/IEA2016 World Energy Outlook report, the commitments of the Paris Agreement are "far from sufficient to limit global warming to less than $2{ }^{\circ} \mathrm{C}$ ".

${ }^{3}$ Statement at the release of the IPCC Fifth Assessment Synthesis Report, 2 November 2014.
} 
dividend" was first formulated by Pearce (1991). The original idea was to tax negative externalities, i.e. carbon emissions, and to use revenues to further reduce other distorsive taxes. If positive impacts ("revenue recycling effect") could outweigh negative impacts ("tax interaction effects"), then a "strong" double dividend could be obtained, sensu 45 Goulder (1994).

Early work on these issues has been largely theoretical, with seminal articles from Bovenberg and de Mooij (1994) and Bovenberg and Van der Ploeg (1996), concluding against the possibility of a double dividend, unless labour is a better substitute for polluting inputs than capital. Literature reviews of these early works have been conducted 50 by Goulder (1994) and Chiroleu-Assouline (2001). This literature then evolved with the growing concern of unemployment and the development of numerical calculation. The theme of the employment dividend has become increasingly important, with increasing debates around the potential for "green jobs". While previous theoretical models were often highly stylized, numerical models explored employment impacts in a more quantified manner, incorporating the issues of sectoral differences and interindustry dependencies.

Results from this literature are still mixed, and it is difficult to find robust conclusions. Two main reasons explain this difficulty. The first one is the multiplicity of situations studied: analyses refer to different countries, with various scenarios and data hypotheses on technology costs or production structures. The second reason relates to the variety

${ }_{60}$ of models employed. In particular, two main families of economic models are broadly used in the energy-employment literature: Input-Output (IO) models and Computable General Equilibrium (CGE) models. For IO models, we can quote the works of Hillebrand et al. (2006); Scott et al. (2008); de Arce et al. (2012); Markaki et al. (2013); Hartwig and Kockat (2016); Yushchenko and Patel (2016); Li and Jiang (2016) and Garrett-Peltier

65 (2017) For the CGE models, there are the works reviewed in the meta-analysis of Patuelli et al. (2005), or more recently the works of Sancho (2010); Böhringer et al. (2013); Chen et al. (2016) and those in the literature review of Freire-González (2018). .

It is difficult to disentangle which results stem from the model and which do not. Yet, these two types of model continue to be used in academic publications and reports 70 to policy makers - without comparison between the two. Our aim is thus to understand the economic mechanisms of job creation due to investment shifts. Why would divesting from fossil fuels and favouring low-carbon sectors create jobs? Do the arguments about local jobs, domestic sources of energy and labour-intensive technologies hold in a general equilibrium?

Our analysis should enable us to determine robust results across both types of model, IO and CGE, and to highlight their differences. IO models can be considered a corner case of the CGE, i.e. a CGE model with very specific assumptions. But these assumptions are so specific that IO and CGE can also be considered as different types of models. The advantage of IO models is their ease of use and transparency. They are quick to

so set up, and can easily be combined with technico-economic models (Scott et al., 2008; Yushchenko and Patel, 2016). In comparison, CGE models take into account a greater number of economic feedbacks, at the cost of a lower readability - which is why they are sometimes called "black boxes" (Fæhn, 2015). These respective qualities explain the coexistence of these two types of models in the academic sphere. But what does this ${ }_{85}$ trade-off between simplicity and feedbacks implies in terms of employment results?

The literature comparing Input-Output and CGE models is quite narrow, but concludes mainly to a much stronger effect in IO models in case of increased investment. 
These include Partridge and Rickman (1998), O'Hara and Pirog (2013) and Dwyer et al. (2005). In particular, Dwyer et al. (2005) discuss the differences between IO and CGE

90 models, and then conduct a comparative evaluation of the effects on employment of a Grand Prix. They find that the employment multiplier is 4.64 times higher in the IO model. In general, these comparison works examine the effect of increased investment. They are interested in subjects and sectors very different from those concerned by the energy transition. Finally, they quantify only the net overall impact, without distinguishing 95 the economic effects at work.

Our work is innovative in three ways. First, we disentangle three economic mechanisms in the study of employment impacts. We look separately at the effects related to (i) labour intensity relative to capital, (ii) wage levels, and (ii) import rates. This distinction between the three effects has never been made to our knowledge, and is therefore 100 a new contribution to the literature. This work helps to refine the understanding of the economic mechanisms at work in the CGE and IO models.

Second, we consider the effect on employment of reallocating final demand, rather than the effect of an increase in demand. The study of a reallocation seems to us relevant with regard to the current stakes of shifting investment flows in the energy sector. The intuitions of the existing literature, which relate to an increase in demand, do not necessarily apply. In the case of an increase in final demand, the feedbacks in the CGE model tend to limit the net changes relative to the IO model, via price and wage inflation. In the case of reallocation, this net effect is not as clear-cut: job increases in one sector will go hand in hand with decreases in other sectors, and the net effect of 110 different feedbacks is not intuitive.

Finally, we propose a numerical analysis of two climate policies: the deployment of photovoltaic solar panels to promote self-consumption and weatherization. This analysis provides a quantified answer, based on the specific characteristics of these sectors, to the gap between the CGE and Input-Output models. To assess investment flows, we

115 use the "synthetic industry approach" method, recently formalized by Garrett-Peltier (2017). This new approach avoids the problem, highlighted by Cameron and van der Zwaan (2015), of the availability of renewable energy data. The data we use could give new results, since the high labour content of renewable energies and building retrofitting is often presented as a key lever for job creation. Finally, combined with the previous, 120 more theoretical analysis, our quantification makes it possible to take a critical look at the existing literature.

In the remainder of the article, we begin with the more theoretical approach in section 2. We justify the choice of the three mechanisms studied (2.1), then use stylized CGE models to assess the employment impact of reallocating investments to more labourintensive and less capital-intensive sectors (2.2), to low-wage sectors (2.3) and to low importing sectors (2.4). In Section 3, we use a comprehensive CGE model to numerically compare two policies: photovoltaic solar panel installation and weatherization. Section 4 discusses the results and concludes. 


\section{Three case studies}

\subsection{Motivation}

In input-output analysis, the link between job creation (in full-time equivalent jobs fte) and the variation in total final demand $\Delta \boldsymbol{d}^{t}$ is given by Leontief's relationship:

$$
\Delta \boldsymbol{f t e}=\tilde{\boldsymbol{e}}^{T r} \cdot\left(\boldsymbol{I}-\boldsymbol{A}^{d}\right)^{-1} \cdot\left(\boldsymbol{I}-\widehat{\boldsymbol{\tau}^{m}}\right) \cdot \Delta \boldsymbol{d}^{t}
$$

In this matrix formula, bold and lower-case letters indicate a column vector; bold and capital letters a square matrix. $I$ is the identity matrix, ${ }^{T r}$ represents the transposition operator and ^ the operator which transforms a vector into a diagonal matrix. Exponents $m, d$ and $t$ indicate whether the value refers to imports $(m)$, domestic perimeter $(d)$ or

135 the total of both $(t) . \boldsymbol{A}^{d}$ is the matrix of domestic technical coefficients, $\boldsymbol{\tau}^{m}$ the vector of import rates, and $\tilde{\boldsymbol{e}}$ is the vector of the number of full-time equivalents per unit of output in each sector.

Let's slightly modify this usual equation to make the economic intuitions stand out better. If we call $\boldsymbol{e}$ the vector of the number of FTEs per unit of value added, then we can rewrite the previous equation :

$$
\Delta \boldsymbol{f t e}=\boldsymbol{e}^{T r} \cdot \boldsymbol{Q}^{d} \cdot\left(\boldsymbol{I}-\widehat{\boldsymbol{\tau}^{m}}\right) \cdot \Delta \boldsymbol{d}^{t}
$$

with $\boldsymbol{Q}^{d}=\left(\boldsymbol{I}-\boldsymbol{i}^{T r} \cdot \boldsymbol{A}^{d}\right) \cdot\left(\boldsymbol{I}-\boldsymbol{A}^{d}\right)^{-1}$, where $\boldsymbol{i}$ is a column vector composed only of 1 (see demonstration A.1 in appendix). The $\boldsymbol{Q}^{d}$ matrix is an allocation matrix: each of ${ }_{140}$ its columns $j$ indicates in which sectors $i$ is generated the value added to meet the final demand addressed to the $j$ sector. Remember that total domestic demand is equal to total domestic value added, so $\boldsymbol{Q}^{d}$ only allocates final demand. This allocation role is illustrated by the fact that $\boldsymbol{Q}^{d}$ directly links value added and final demand: $\boldsymbol{v a}=\boldsymbol{Q}^{d} \cdot \boldsymbol{d}^{d}$.

This new formulation in equation 1 illustrates how input-output models work. Reading it from right to left, it shows that a change in final demand leads to a change in domestic demand (net of imports) $\Delta \boldsymbol{d}^{d}=\left(1-\widehat{\boldsymbol{\tau}^{m}}\right) \cdot \Delta \boldsymbol{d}^{t}$. This domestic demand is then allocated to the different sectors by the $\boldsymbol{Q}^{\boldsymbol{d}}$ matrix, where it generates value added. Finally, this added value creates jobs, depending on the direct intensity of employment $\boldsymbol{e}$ of each sector. This decomposition illustrates the key role of import rates and jobs per 150 unit of value added in IO models.

Let us take the simple case of an economy with two sectors, and without intermediate consumption. In this case, $\boldsymbol{A}=0$, and $\boldsymbol{Q}^{d}$ becomes the identity matrix. Moving final demand from sector 1 to sector 2 generates employment if and only if (demonstration in appendix A.2):

$$
e_{2} \cdot\left(1-\tau_{2}\right)>e_{1} \cdot\left(1-\tau_{1}\right)
$$

We can further decompose the $\boldsymbol{e}$ vector as the ratio of two quantities: the share of labour in value added $\tau^{l}$ divided by the average wage $w$ in each sector. Mathematically, one can write:

$$
e_{i}=\frac{f t e_{i}}{v a_{i}}=\frac{f t e_{i}}{l_{i}} \cdot \frac{l_{i}}{v a_{i}}=\frac{\tau_{i}^{l}}{w_{i}}
$$


The previous inequation can then be rewritten:

$$
\frac{\tau_{2}^{l}}{w_{2}} \cdot\left(1-\tau_{2}^{m}\right)>\frac{\tau_{1}^{l}}{w_{1}} \cdot\left(1-\tau_{1}^{m}\right)
$$

We see in this example that, in input-output analysis, job creation passes through three channels. Employment can be created if final demand is reallocated to a sector with:

- a greater share of work in value added (i.e. a sector that is not capital-intensive)

- lower wages

- a lower import rate

But do these results stand in a CGE model? This question motivates the approach followed in the rest of this section. We examine each of these three effects in turn, comparing each time a stylized CGE model with an input-output model. The impact of targeting sectors with a high share of labour is analysed in subsection 2.2. The effects of low salaries are studied in subsection 2.3. The role of trade is considered in subsection 2.4 .

\subsection{Labour vs capital: Targeting labour-intensive sectors}

What are the employment impact of encouraging sectors with a high labour intensity and a low capital intensity? On the one hand, it may seem intuitive that spending final demand in labour-intensive sectors will create more jobs by increasing labour demand. On the other hand, such a policy also means to encourage less productive sectors. This could imply lower production and thus less employment. Which effect will dominate is not intuitive.

As an input-output model can be considered a special case of a CGE, we can put side by side the corresponding equations of each model in order to highlight their differences. Some differences are shown in table 1 and the full set of equations is presented in table 8 in appendix. The main differences are:

- Resource availability (eq. 1 and 2). In IO, all productions factors are available ad infinitum, at a fixed price. On the contrary, in CGE, resources are scarce. This scarcity can be represented by a fixed amount of supply, as is done for capital in equation 2; or with a price increasing with the volume supplied. The wage curve, which is often used in the literature and represented in equation 3 here to represent labour supply, falls into the second category.

- Factor substitutability (eq. 3 and 4). In IO, the ratios of labour, capital and intermediate inputs are fixed. The use of Leontief production function also leads to proportional demand function. In a CGE, the production function can embed substitution mechanisms, based on relative prices. This is mostly done through the CES function. Energy-economy models often use Cobb-Douglas functions - that is, CES with a unitary elasticity of substitution. 
Table 1: Comparative equations of IO and CGE models.

\begin{tabular}{llll}
\hline Num & Description & CGE 1 & IO model \\
\hline eq1 & Capital supply & $F F_{C A P}=\overline{F F_{C A P}}$ & $p_{C a p}^{f}=1$ \\
eq2 & Labour supply & $\log \left(\frac{p_{L A B}^{f}}{p c}\right)=-\gamma \cdot \log \left(\frac{U}{U^{0}}\right)$ & $p_{L a b}^{f}=1$ \\
eq3 & Production function & $Z_{j}=s c Z_{j} \cdot\left(\sum_{h} \delta_{h, j} F_{h, j}^{\rho^{z}}\right)^{1 / \rho^{z}}$ & $Z_{j}=\min _{h}\left(\frac{F_{h, j}}{a_{h, j}}\right)$ \\
eq4 & Factor demand (K and L) & $F_{h, j}=\left(s c Z_{j}^{\rho^{z}} \delta_{h, j} p_{j}^{z} / p_{h}^{f}\right)^{\sigma^{z}} Z_{j}$ & $F_{h, j}=a_{h, j} \cdot Z_{j}$ \\
eq5 & Household demand & $C_{i}=\frac{\alpha_{i}}{p_{i}^{c}}\left(\operatorname{Inc}-S^{p}\right)$ & $C_{i}=\overline{C_{i}}$ \\
\hline
\end{tabular}

$Z_{j}$ is the output of the j-th good, $F_{h, j}$ the h-th factor input by the j-th firm, $F F_{h}$ the h-th factor supply, Inc, represents household income, $C_{i}$ household consumption of the i-th good and $S^{p}$ private savings. More information on this model can be found in appendix, section A.4.

The budget constraint, shown in equation 5, is endogenous in the CGE: households adapt their expenditure depending on their net income after savings. In IO, household consumption is exogenous, but the budget constraint is also respected in a closed economy, due to the linearity of the model: an increase in consumption or investment leads to an equal increase in income.

In input-output, investment is determined exogenously. In order to draw a parallel between IO and CGE, we also model investment in each sector as exogenous in our CGE, in volumes. Savings are then set to be equal to total investment. This macroeconomic closure driven by investment implies that savings will be exogenous in volumes as well,

195 but the rate of savings might vary. In its discussion of macroeconomic closures, Sen (1963, p. 57) classified such models with investment-driven closure and unemployment as "general theory models". Fixing investment exogenously allows to easily represent sectoral reallocation of investments, and it is widely used in the literature (Lehr et al., 2008, 2012).

Given these differences between CGE and IO, how far are CGE results from IO results? In order to study the effect of capital intensity in isolation, we consider a simple CGE model of a closed economy. This economy is composed of just two sectors which differ only by their capital/labour ratio. It is represented by the social accounting matrix (SAM) in table 2. In this case, we do not consider inter-industry transactions. This helps identify clearly which sector is more job-intensive (normalizing one monetary unit of labour to one job). In this case, it is sector $\mathrm{S} 1$, with $9 / 14=0.64$ jobs per unit of value added, against $4 / 9=0.44$ jobs per unit of value added for S2. Studying a case without inter-industry transactions is not a loss of generality, as this matrix of inter-industry transactions is only a reallocation matrix of final demand and value added (as explained in section 2.1).

Starting from the SAM in table 2, we compare the impacts of shifting one unit of investment, in volume, from sector $\mathrm{S} 2$ towards the more job-intensive sector $\mathrm{S} 1$. In the IO model, such a shift entails an increase in employment of 0.20 .

With our CGE model, the same shock leads to an increase in employment of 0.17 in our central case - that is with a wage curve elasticity of 0.1 , as recommended by Blanchflower and Oswald (2005), and a CES production function with an elasticity of 0.5, in line with the empirical estimate of (Antràs, 2004) and van der Werf (2008). 
Table 2: SAM of a two-good, two-sector economy

\begin{tabular}{llllllll}
\hline & S1 & S2 & LAB & CAP & HOH & INV & Total \\
\hline S1 & & & & & 9 & 5 & 14 \\
S2 & & & & & 4 & 5 & 9 \\
LAB & 9 & 4 & & & & & 13 \\
CAP & 5 & 5 & & & & & 1 \\
HOH & & & 13 & 10 & & & 23 \\
INV & & & & & 10 & & 10 \\
Total & 14 & 9 & 13 & 10 & 23 & 10 & \\
\hline
\end{tabular}

LAB: labour compensations; CAP: capital compensations; HOH: households; INV: investment.

We make several runs to test the sensitivity of CGE results to these parameters. For the value of elasticity between capital and labour, we consider three cases of a CES production function: a Leontief function, as used in IO models, which implies that capital and labour are perfect complements; a Cobb-Douglas, which is the function used by a majority of climate-energy CGE and means an elasticity of one. For the wage curve elasticity, we consider the cases $\gamma=0$, to represent fixed wages as in IO models, and $\gamma=0.05$ as an intermediate case.

The sensitivity of employment results are shown in figure 1. This figure highlights that switching final demand towards more job-intensive sectors generates a positive employment impact on employment for both models. The intuition of increasing labour demand by targeting job-intensive sectors holds in a general equilibrium framework.

It also shows that, depending on the choice of parameters for scarcity (of labour and capital, in the supply functions) and substitutability (between labour and capital, in the production function), the job impacts of shifting demand can be higher in the CGE or higher in IO. This contradicts the idea that IO models are always more favourable than CGE. It reflects the fact that there are additional feedbacks in the CGE, compared to $\mathrm{IO}$, which do not pull in the same direction.

235 On the one hand, the scarcity of labour and capital in the CGE implies that an investment shift towards the labour-intensive sector will increase wages and decrease capital price. Combined with factor substitutability, this leads to a reduction of labour in the production function - a negative feedback on employment compared to IO.

On the other hand, the decrease in capital price in the CGE increases the purchasing 240 power and thus the incentive to work, triggering a positive feedback on labour supply. To further demonstrate that point, we consider a case where the price of capital is fixed and the quantity of capital is infinite. In such a case, a shift in final demand towards the labour-intensive sector never create jobs in the CGE.

In conclusion of this section, both CGE and input-output analysis conclude to job 245 creation when there is a shift in investment towards more job-intensive sectors. The amount of jobs created is similar between the two models. However, this convergence hides two divergent mechanisms. The scarcity of labour in CGE models reduces the employment boost of shifting demand, but this shift also generates positive impacts by lowering pressure on the scarce capital. 


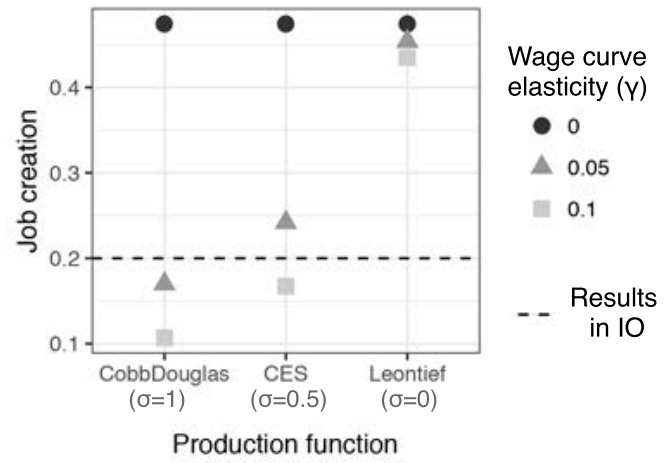

Figure 1: Job creation when shifting final demand towards solar or weatherization: impacts of wage curve elasticity and production function. The dotted line represents job creation with an IO model.

\subsection{Encouraging sectors with low wages}

In this section, we explore the impact of wages and labour skills on employment. What is the net effect on employment of targeting sectors which are job-intensive because of low salaries?

One explanation for the sectoral wage difference is the difference of labour skills required in each sector. In a neoclassical framework, higher skills lead to higher productivity and higher wages. Allocating final demand to sectors with low wages may allow to increase employment by sharing labour revenues (for example, hiring two persons instead of one for the same job, but for half the wage). However, this shift also implies to target less productive sectors, with a potentially negative macroeconomic feedback.

To investigate these impacts, we expand the model of the previous section in order to account for wage differences between skills and sectors. In the previous section, our CGE formulation had only one type of labour and assumed a unique wage across all sectors. Here, we model two levels of qualification in the labour force: low skilled and high skilled workers. In each sector, these two types of workers are involved, but their respective shares vary. More specifically, we consider an economy in which capital and labour remuneration are identical in the two sectors, but we suppose that there is a higher share of qualified workers in sector S2 than in S1. Because of this higher share of skilled workers in S2, the average wage is higher in S2 and there are less jobs for the same amount of labour compensation. In our example, the average salary is twice as high in sector S2 as in sector S1. The two labour skills are modelled as imperfect substitutes and form a labour composite which is then aggregated with capital. The supply of workers of each type is modelled with a wage curve. More information on this model can be found in appendix A.5, including the SAM used (in table 9) and initial labour endowments (in table 10).

In this CGE, shifting one unit of final demand towards S1 generates a positive impact of employment of 0.05 in our central case (i.e. with a wage curve elasticity of 0.1 for both types of labour). As long as the wage curve elasticities of the two labour skills are equal, this value remains positive, between 0.04 and 0.065 (cf. figure $2 \mathrm{a}$ ).

The impact on employment vary more if the wage curve elasticities differ between labour skills. Empirically, such variations have been observed depending on education, 


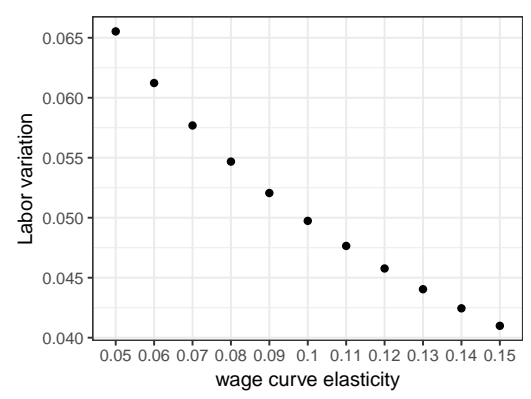

(a) Labour variation with identical wage curve elasticities across labour skills

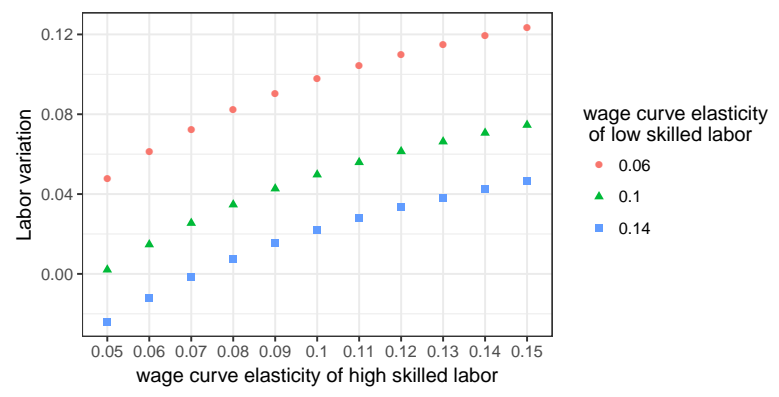

(b) Labour variation with different wage curve elasticities across labour skills

Figure 2: Labour impacts of shifting demand towards lower-paying sectors: sensitivity to the wage curve elasticity

age, union strength and private/public status (Blanchflower and Oswald, 2005; Kingdon and Knight, 2006). This elasticity thus varies between countries. At one extreme, if the wage curve elasticity of high skilled labour is much lower (e.g. 0.05 vs 0.12 for low skilled labour), the impact of shifting demand can be negative. At the other extreme, if the wage curve elasticity of high skilled labour is much higher, then the positive effect on job creation is even more pronounced, going up to 0.11 in our example for respective elasticity of 0.06 and 0.12 (cf. figure $2 \mathrm{~b}$ ).

With the IO model, shifting one unit of final demand from S2 to S1 yields a positive employment impact of 0.143 , against 0.05 in our CGE central case. This comparison highlights that both model CGE and IO can conclude to job creation when targeting sectors with low salaries, but IO models yield a significantly higher estimate of this positive impact.

To explain this difference, the intuition is that flexible wages in a CGE reduce the employment boost observed in Input-Output. The higher demand of low-skilled workers leads to an increase in their salary, with a negative feedback on the creation of low-skilled jobs. The lower demand for high-skilled workers reduces their salary, thus reducing the number of job destruction for high-skilled workers. Overall, the price effect contributes in both ways to limiting the employment shifts observed in the IO model.

The importance of wage flexibility can be further highlighted by setting wages as constant in the CGE model (i.e. setting the wage curve elasticity to zero). In such a case, the employment impacts are equal in the CGE and in the IO model, regardless of the elasticity of substitution between high skilled and low skilled labours.

Wage elasticity is thus the key source of divergence between IO and CGE models when assessing the employment impacts of targeting sectors with low salaries. IO models may provide a better picture of short term impacts, while CGE gives a view of long term equilibrium, once salaries have adjusted. 


\subsection{The impact of trade: favouring local production?}

Is it possible to create jobs by shifting investment towards sectors with low import rates? In section 2.1, we showed that, in IO models, reducing imports increases domestic value added and employment. Does this result hold in a CGE?

In an open economy, additional differences appear between IO and CGE models, compared to the closed economy of section 2.2 , which are highlighted in table 3 . These key differences are:

- Trade closure: In a CGE, the trade balance is fixed. By contrast, there is no trade closure in an IO model (cf. equation 10 in table 3 ).

- Export demand: In IO, exports are exogenous, and generally fixed as constant. In a CGE, exports are the results of a domestic supply function and an elastic demand from the rest of the world. Taking the assumption of a small country, this demand is perfectly elastic - which is the exact opposite of the fixed exports in IO (cf. equation 15 in table 3 ).

- Traded good substitutability: In a CGE, imports compete with the domestic good. They are imperfect substitutes, whose relative shares vary based on their relative price. Exports compete on the world market. In IO, there is no such competition: imports represent a fixed share of output, and exports are fixed (equations $18,19,21$ and 22 in table 3$)$.

Table 3: Comparative equations of IO and CGE models for an open economy. We use a modelling framework similar to the standard CGE presented in the textbook by Hosoe et al. (2010). The full set of equations is shown in table 11 in appendix.

\begin{tabular}{llll}
\hline & Equation purpose & $\mathrm{CGE}$ & $\mathrm{IO}$ \\
\hline eq10 & Trade closure & $S^{f}=\overline{S^{f}}$ & \\
eq15 & Export demand & $p_{i}^{e}=\epsilon \cdot \overline{p_{i}^{W e}}$ & $E_{i}=\overline{E_{i}}$ \\
eq18 & Armington function & $Q_{i}=s c Q_{i}\left(\alpha_{i}^{m} M_{i}^{\rho_{Q}}+\alpha_{i}^{d} D_{i}^{\rho_{Q}}\right)^{1 / \rho_{Q}}$ & $Q_{i}=M_{i}+D_{i}$ \\
eq19 & Imports demand & $M_{i}=\left(s c Q_{i}^{\rho_{Q}} \cdot \alpha_{i}^{m} \cdot \frac{p_{i}^{Q}}{p_{i}^{m}}\right)^{\sigma_{Q}} Q_{i}$ & $M_{i}=\lambda_{i}^{m}\left(Q_{i}+E_{i}\right)$ \\
eq21 & CET function & $Z_{i}=\theta_{i} \cdot\left(\xi_{i}^{e} \cdot E_{i}^{\phi_{i}}+\xi_{i}^{d} \cdot D_{i}^{\phi_{i}}\right)^{\left(1 / \phi_{i}\right)}$ & $Z_{i}=E_{i}+D_{i}$ \\
eq22 & Supply of E & $E_{i}=\left(\theta_{i}^{\phi_{i}} \cdot \xi_{i}^{e} p_{i}^{z} / p_{i}^{e}\right)^{\left(1 /\left(1-\phi_{i}\right)\right)} Z_{i}$ & \\
\hline
\end{tabular}

To estimate the impact of these differences in the modelling of trade, we consider again a two-sector, two-good economy. In this case, we suppose that the two sectors are identical, except for their share of imports. The corresponding SAM is represented in table 12 in appendix. Again, we set the matrix of intermediate consumption to zero in order to make our case more intuitive, without loss of generality.

We now simulate a shift of one unit of investment from S2 towards S1, the sector with lower import rates. Detailed results are available in appendix A.6.5, but we highlight here the main idea.

In IO, there is a positive effect of targeting the sector with lower import rates. The total amount of imports is reduced. Since exports remain constant by assumption, the net balance of trade improves. These import reductions translate into higher domestic 
value added, which in turn generate more jobs. Overall, there is an increase in labour in IO (see table 13 in appendix).

In our CGE, the investment shift generates adjustments in trade patterns and production, but leaves net employment unchanged. There is decrease in imports in S2, but also a decrease in exports for the same sector: the fewer resources do not affect domestic consumption, but translates in less goods available for export. A mirror effect occurs in $\mathrm{S} 1$, with higher imports and exports. Capital and labour shift from S2 to S1 to meet the shift in demand, but these sectoral movements do not translate into any net job creation. Detailed results are given in table 14 in appendix.

However, this substitution between exports and imports is only possible if the sector concerned is itself an exporter. But this is not the case for all sectors. For example, the construction sector (which includes weatherization) has low imports and low exports. We explore such a case with another stylized example, presented in appendix A.6.6. In this situation, a shift in investment from S2 to S1 generates changes which are similar to the case with exports, only this time a small employment creation is also observed: 0.02 units, vs 0.07 units with the IO model. The absence of exports translates into higher prices and wages, which pushes labour supply up.

The importance of the trade closure rule deserves some further comments. Inputoutput analyses act as if the budget constraint of trade balance does not hold. The intuitive criticism is that trade balance has to get balanced eventually. A country cannot run a trade deficit (or surplus) indefinitely, and a balancing feedback occurs, often through an evolution of the exchange rate: this is the external devaluation. Trying to improve the trade balance will only generate short-term benefits, which will vanish as soon as the exchange rate adapts.

However, it is important to specify what is the time horizon of this "eventually". The closure with fixed foreign savings is just a simplified representation of market adjustment mechanisms, and such a convergence is sometimes slow. The continuous trade deficit of the United States is a counter-example of this budget rule. Other counter-examples 365 include the regimes of fixed exchanges rates, or common currency areas. In such cases, restoring trade balance can occur through internal devaluation, rather than external devaluation. But this process can take years or even decades. For example, in the European Union, the current accounts of France and Germany have continuously diverged since 1999, as shown in figure 3. Within this context of "unbearable slowness of internal 370 devaluation" (Krugman, 2012), a hypothesis of fixed unbalanced trade might be a better short-term or mid-term approximation than a fixed budget constraint.

To sum up, our comparison of trade patterns in IO and CGE models thus highlights that IO models provide a good approximation of CGE as to the sectoral shifts in labour and capital, but tend to underestimate the crowding out effects between imports and 375 exports. In IO, a reduction in imports is a net benefit, with a positive effect on value added and net employment. In our CGE, there is substitution between exports, imports and the domestic good, so that a decrease in imports leads to a decrease in exports. There is also a switch of capital and labour towards the sector in which final demand increases, but with no net employment benefit - unless the targeted sector does not export, in which 380 case there are positive job gains in CGE, although smaller than with IO models. 


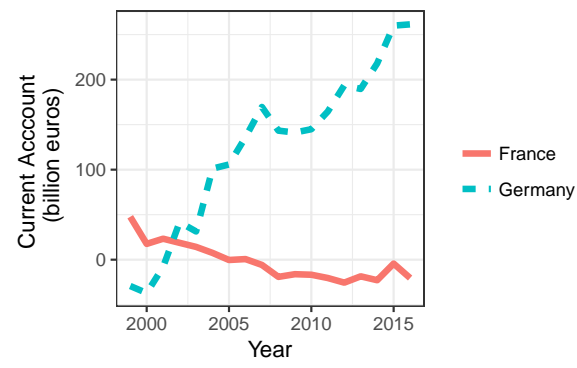

Figure 3: Current account of France and Germany since 1999 Sources : Eurostat, database tipsbp20

\section{Full model comparison}

In this section, we turn to a more quantitative analysis of the employment impact of CGE and IO models. The stylized examples of the previous sections have helped identify the three major determinants of employment creation in IO models, and how they change in a CGE model. We now turn to a comparison of fully-fledged CGE and IO models, with 58 sectors. This section will thus bring together the previous parts, adding up the effects and identifying their possible interactions. It will provide quantitative results on job creation, while the previous section was more qualitative.

In addition, a complete model takes into account some aspects that have so far been omitted. In particular, this last CGE model will consider the role of the government and tax collection. This aspect is often neglected in input-output analyses. With IO models, the presence of taxes or subsidies can induce a bias in employment content, artificially raising or reducing it for some sectors (Perrier and Quirion, 2017). To avoid this bias, the change in government revenues should be corrected in IO analyses, but this aspect is rarely mentioned and even less dealt with. By contrast, in the CGE, we will consider that the government's budget constraint is met, taking into account all sources of revenue. Thus, an increase in investment in sectors with low taxes or high subsidies will lead to an increase in direct taxes on households, so that government revenues remain constant.

\subsection{Scenario}

400 We focus on two case studies: the improvement of building weatherization, and the installation of solar panels on roofs. An investment in weatherization decreases the need for heating, and thus the consumption of gas or electricity, depending on the heating system. Similarly, an investment in private solar panels will lead to self-sufficiency in power, thus reducing electricity consumption from the network. In each case, we suppose 405 that a cost-effective investment exists; in other words, that the discounted benefits of reduced consumption are equal to the initial investment costs. This assumption allows us to focus on the difference in employment impacts, all other things being equal. And this seems plausible in both cases: the rapidly-falling costs of solar panels have made 
this technology competitive, or close to competitive, in many countries ${ }^{4}$; weatherization 410 can also be competitive ${ }^{5}$.

We also suppose that power and heat production are determined by the technological environment and by the "basic needs" to heat a house and power all appliances. From a modelling perspective, we use a Stone-Geary utility function, with a subsistence consumption level (the basic needs) for the electricity, gas and heat sector. With these ${ }_{415}$ hypotheses, the exogenous basic need is formally equivalent to an exogenous investment. The results of the previous sections can thus be applied.

We study a scenario with an investment of one billion euros in weatherization or solar panels, and a (discounted) reduction in consumption of one billion in the power, gas and heat sector. The results are compared to the initial equilibrium.

\section{${ }_{420}$ 3.2. CGE model description}

Our CGE model is based on a textbook by Hosoe et al. (2010), the equations of which are available in the GAMS community ${ }^{6}$ online model library. We use this standard model in order to avoid as far as possible any "black-box" criticism, and to provide general, standard results.

Our CGE model is based on the exact same input-output table used in the IO analysis. But it adds an additional layer with flexible prices and utility maximization of households.

Government taxes production, final household consumption and investment at constant rates. It also directly taxes a fraction of household revenues. Capital supply is fixed.

This model incorporates the assumption of a small economy, which means that foreign prices are considered fixed. Supply of imports and demand for exports are assumed to be infinitely elastic. Demand for imports is represented through an Armington specification. Exports and domestic goods are assumed to be imperfectly substitutable, as represented by a CET function.

435 We make only three changes to Hosoe et al. (2010)'s textbook model, in order to adapt it to our research question. First, we expand the modelling of the labour market. We introduce two skill levels for labour: low and high, in order to represent and explain wage differences between sectors. And we replace the assumption of fixed labour by a wage curve, in order to study the impact of investment policies on employment. Second, we modify the macroeconomic closure. Instead of closure being driven by a fixed saving rate, we use a closure based on exogenous investments (as was the case with our small-scale examples). This new closure allows a better parallel with IO models, in which investments are exogenous; and it is commonly used in the literature on green jobs (Lehr et al., 2008, 2012). Third, we make government consumption exogenous and constant, in order to 445 avoid variations in government expenditure which may cloud results for employment. The government adjusts its budget by choosing the rate of direct tax on households. It also collects taxes from production and consumption, but at fixed rates.

\footnotetext{
${ }^{4}$ According to the International Energy Agency and Nuclear Energy Agency (2015), "at the low-end, costs [of renewable technologies] are in line with or even below baseload technologies".

${ }^{5}$ In another report, the International Energy Agency (2013) states that "Some of the technologies needed to transform the buildings sector are already commercially available and cost effective, with payback periods of less than five years"

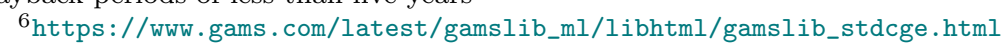


More information on this model can be found in appendix A.7.

\subsubsection{Data}

450

To calibrate our model, we use four data sources in our analysis. The first three are collected and provided by the French national institute of statistics, the INSEE. The last one is from Garrett-Peltier (2017).

- The 2013 input-output tables for France, at the 64 product levels, based on the NACE Rev. 2 classification. One table represents the French domestic balance between supply and use, and the other represents the total French economy. The difference between these two tables yields the import table.

- The number of full-time equivalent (FTE) jobs, at the same level of disaggregation and with the same classification.

- The amount of tax collected by the government. We use the table of integrated economic accounts produced by INSEE. ${ }^{\text {? }}$

- Finally, the cost structures of solar PV and weatherization. We use the literature review provided by Garrett-Peltier (2017).

However, to avoid issues relating to negative values, we aggregate some sectors (see appendix A.7.1 for more details). With these modifications, we end up with 58 sectors. 465 We apply the same grouping to the employment data.

We estimate the investment vectors in weatherization and solar PV from Pollin et al. (2015). These vectors are shown in table 4 .

Table 4: IO vectors from Pollin et al. (2015) as quoted by Garrett-Peltier (2017)

\begin{tabular}{lcc}
\hline Label & Solar & Weatherization \\
\hline Construction & 0.3 & 1 \\
Fabricated metal products & 0.175 & \\
Machinery & 0.175 & \\
Computer and electronic products & 0.175 & \\
Miscellaneous professional, scien- & 0.175 & \\
tific, and technical services & & \\
\hline
\end{tabular}

\subsubsection{Preliminary analysis of energy sectors}

Before turning to the numerical application, let us examine a few metrics to understand 470 the mechanisms at work, in line with the analysis in section 2. The import rate, share of labour, wages and employment content of the sectors under consideration are shown in table 5. For solar and weatherization, the ratios are based on the synthetic industry approach of Garrett-Peltier (2017): we use a weighted average of existing sectors, using

\footnotetext{
${ }^{7}$ https://www.insee.fr/en/statistiques $/ 2561550$ ? sommaire=2387999
} 
the weights indicated in table 4 . The import rate, wages and employment levels are

direct measures for each sector. They represent only the first-round effect, not all the inter-industry effects. But they provide a first-order approximation as to the employment impacts of targeting each sector.

In France, the electricity and gas sector has a low share of labour in value added, as well as high salaries, compared to solar panels and weatherization. As shown in our 480 previous analyses in section 2, these two factors will induce job creation when investing in solar or weatherization, at the expense of the traditional electricity or gas sector.

The third factor, import rates, is higher for solar panels: $23 \%$ against $0 \%$ for weatherization and $0.5 \%$ for electricity and gas (for electricity, only a small share of final consumption is imported). In the CGE, the high import rate of solar panels should not 485 play a major role (cf. section 2.4), so we can guess the net employment effect of this demand shift will be positive - unless some second-order effect dominate. In the IO model, the net employment effect of supporting weatherization is likely to be positive, as the three factors studied previously converge in this direction. For solar, the high import rate might counter the positive effect of low wages and high labour share, so the sign of

490 the net employment effect cannot be anticipated; however, we can guess that the employment effect will be higher for weatherization than for solar in IO, as weatherization has more favourable direct ratios for each of the three parameters in table 5 .

Table 5: Descriptive direct ratios

\begin{tabular}{|c|c|c|c|}
\hline & $\begin{array}{l}\text { Import } \\
\text { rate }(\%)\end{array}$ & $\begin{array}{l}\text { Share of } \\
\text { labour } \\
\text { in value } \\
\text { added } \\
(\%)\end{array}$ & $\begin{array}{l}\text { Wages } \\
(\mathrm{k} \in / \\
\text { FTE })\end{array}$ \\
\hline Solar & 23 & 81 & 56 \\
\hline Weatherization & 0 & 82 & 48 \\
\hline $\begin{array}{l}\text { Electricity, } \\
\text { gas and air- } \\
\text { conditioning }\end{array}$ & 0.5 & 39.2 & 92.5 \\
\hline
\end{tabular}

\subsection{Results}

We now run the CGE model with central values for all parameters (sensitivity analyses will follow), as well as the IO model. For each model, we compute the number of jobs created by investing one billion euros in the technology indicated in the first column (solar panels or weatherization), and reducing electricity or gas consumption by the same amount. We can then calculate the discrepancy ratio between the two models, i.e. the number of jobs created in IO divided by the number of jobs created in the CGE.

${ }_{500}$ Table 6 shows that encouraging weatherization or the installation of solar panels both generate positive employment impacts. In line with our preliminary analysis, we can link these effects to the higher share of labour in value added, as well as to the lower wages in those sectors, compared to the electricity and gas sector. Second, we measure 
a discrepancy ratio of 1.07 and 1.51 for solar and weatherization respectively. The IO

model yields higher estimates, but the discrepancy is smaller than other values in the literature. For example, Dwyer et al. (2005) found a ratio of 4.6 (but for a very different scenario: he was studying the impacts of a Grand Prix).

Table 6: Employment impacts of investing in solar panels or weatherization (in full-time equivalents for a shift in final demand of one billion euros)

\begin{tabular}{lccc}
\hline Technology & Job creation in CGE* & Job creation in IO & Discrepancy ratio \\
\hline Solar & 4,670 & 5,010 & 1.07 \\
Weatherization & 5,331 & 8,050 & 1.51 \\
\hline
\end{tabular}

*For a capital-labour elasticity $\sigma_{K L}=0.5$ and a wage curve elasticity $\gamma=0.1$

\subsection{Sensitivity analyses}

\subsubsection{Impact of the wage curve and capital-labour elasticity}

The employment results of a shift in final demand are represented in figure 4 for the CGE model.

For all the values considered, there are positive employment impacts, but both the wage curve elasticity and the capital-labour elasticity have a strong influence on results. The employment impact decreases with both wage curve elasticity and capital-labour elasticity. The intuitions for these results have been described in sections 2.2 and 2.3. These results highlight the importance of capital-labour elasticity for employment impacts. van der Werf (2008) made empirical estimations of this elasticity, and found values between 0.2 and 0.6 , depending on the country. He also noted that many CGE models nevertheless use a Cobb-Douglas function, i.e. a unitary elasticity. In our model, using a Cobb-Douglas function leads to underestimating the positive impacts on employment by at least $17 \%$, if the elasticity were in fact 0.6 , and up to $40 \%$, if the elasticity were in fact 0.2 (see appendix 18).

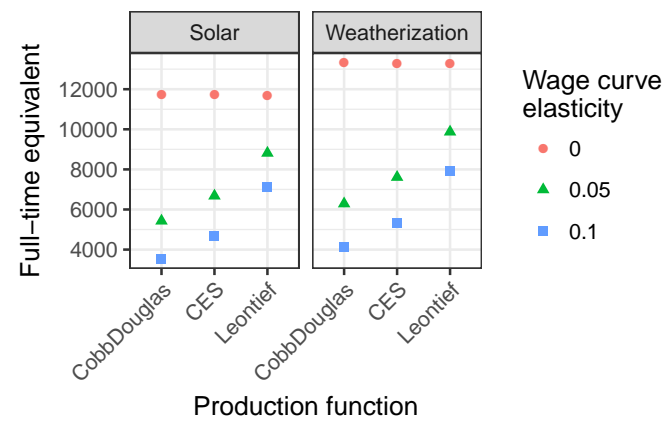

Figure 4: Job creation when shifting final demand towards solar or weatherization: impacts of wage curve elasticity and production function

Figure 4 also indicates that employment impacts can be higher in the CGE than in 
the IO model for low values of the wage curve elasticity and/or of the capital-labour

elasticity. This result goes against the intuition that IO models always provide higher estimates than CGE models. A first explanation for this phenomenon was given in section 2.2: in a CGE, an increase in labour demand also decreases the capital price, thus raising real revenues and the incentive to work. By contrast, in IO models, capital prices are fixed, so this price effect is absent. An additional explanation was provided in section

5302.4 , linked to the impacts of imports. Solar panels have high import rates, but this does not alter their employment impact in CGE - this is only affected by their high labour share in value added and low wages impact. Conversely, in IO models, this high import rate reduces their employment impact.

These two effects combine and help explain the higher job creation in CGE models

535 for low values of wage curve and capital-labour elasticities. These results also show that an IO model is not equivalent to a CGE with Leontief production functions and constant wages: the fixed price of other goods in the IO model, including capital prices, and the differences in the modelling of exports are also sources of major divergences.

\subsubsection{Impact of trade}

540 To explore the impact of trade assumptions, we first run sensitivity analyses on the elasticities of the Armington and the CET functions. Results are shown in figure 9 in appendix A.7.7. In both cases, a higher elasticity reduces job creation, but this impact is limited: tripling one of the elasticities, from 2 to 6 , only reduces job creation by $8 \%$.

\subsubsection{Full sensitivity analysis: difference between CGE and IO}

Finally, we make a full sensitivity analysis, to see the range of possible discrepancy ratios. We make the capital-labour elasticity vary from 0.2 to 0.6 , which is the range observed empirically by van der Werf (2008). We use CET and Armington elasticities between 1.5 and 6 . For all these values, we compute the discrepancy ratio of job creation between the IO and CGE models. The complete table of this sensitivity analysis is available in the supplementary material.

The discrepancy ratio varies between 0.86 and 1.34 for solar, and between 1.22 and 1.87 for weatherization. Thus, the results of IO models seem to provide a good approximation of CGE results for solar, while they are slightly higher for weatherization. The lowest discrepancy ratios are obtained when capital-labour, Armington and CET elasticities are all small.

\section{Summary and concluding remarks}

\subsection{Summary}

In this paper, we examined the employment impacts of reallocating investment towards low-carbon sectors. We showed that there are three economic channels for job creation in input-output modelling: a shift in investment increases employment if it targets sectors with a higher share of labour in value added, lower wages or lower import rates.

Then, we tested to which extent these conclusions stand in a CGE framework. We showed that the sign of the net impact is always the same in the two models, but the 
quantitative difference depends on the economic channel considered. For labour-intensive

sectors, CGE models adds both positive and negative feedbacks compared to IO models, so the difference is small and CGE might lead to more or less job gains than IO, depending on the parameters. For low-wages sectors, the impact is lower in CGE compared to IO. Targeting sectors with lower import rates does not create jobs in a CGE, unless the targeted sector has no exports, in which case there is a positive impact on employment,

570 although smaller than in IO. We highlighted the key differences in modelling assumptions, and linked these assumptions to the differences observed.

Finally, we undertook a quantitative analysis of the employment impacts of investing in weatherization or solar panels, taking into account the benefits in terms of reduced residual consumption of power and gas. We used two models, a fully-fledged CGE and

575 an IO model, and ran them with the same data involving 58 sectors. Our numerical application indicates that both of these investments have a positive effect on employment, a result that is robust across models. For solar, the results are roughly similar in IO and CGE: IO results range from $-14 \%$ to $+34 \%$ (with a central value of $7 \%$ ) compared to the CGE for various parameter values. For weatherization, the results are always higher

580 with the IO model, from $+22 \%$ to $+87 \%$ (with a central value of $51 \%$ ). This positive impact is due to a higher share of labour and lower wages in these sectors, compared to the electricity and gas sector. This analysis also showed that the use of Cobb-Douglas production functions - frequent in CGE modelling but not empirically founded - leads to underestimating employment benefits. In our scenario, this underestimation reaches $58517 \%$ to $40 \%$.

\subsection{Discussion}

The literature often assumes that employment impacts are higher in IO than in CGE models, because the former does not account for all negative feedbacks (Partridge and Rickman, 1998; Dwyer et al., 2005; O'Hara and Pirog, 2013). In this paper, we show 590 that CGE models also have one feedback that is potentially more favourable than in IO: the price of capital is fixed in IO, whereas it could decrease (or increase) in CGE and induce labour-capital substitutions.

The employment benefit of targeting low-wage sectors is mitigated in CGE by the wage feedback. IO models may be appropriate to study short-term effects in case of 595 wage stickiness, if there is a large pool of workers and/or if training is fast, or for changes in demand which are not too large. In such case, IO models seem to provide a good first-order approximation of CGE models. Otherwise, using IO models might lead to overestimating the low-wage effect.

The effect of trade appears to be nil in CGE, while a reduction in imports provides a boost of value added and employment with IO models. This difference in trade comes the diverging assumptions about the trade balance closure. The fixed trade deficit in a CGE seems more appropriate to model countries with flexible exchange rates and study the long-term impact of a policy. The flexible deficit of IO seems suited to analyse shortterm to mid-term impacts for countries with a fixed exchange rate or sharing a common 605 currency.

From a quantitative point of view, the two models give much less divergent results than the previous estimates in the literature. This difference can be explained both by the object of the study (a shift in final demand rather than an increase) and by the 
sectors concerned. IO models might thus be a reasonable approximation of CGE models to estimate the employment impacts of shifting demand, at least in these two sectors.

Our approach suffers from obvious limitations. We do not investigate all the possible modelling specifications of the labour market. Nevertheless, we believe that the wage curve specification we have examined provides interesting results because this framework is widely used by the CGE modelling community. Our representation of trade has re${ }_{615}$ mained simple. Finally, our models lack transitory effects such as sticky prices or wage adjustments.

From a policy perspective, our findings indicate that positive employment impacts can be achieved by shifting investment towards labour-intensive or low-paid sectors. Targeting low-carbon sectors with such characteristics could therefore produce an employment 620 double dividend.

Our results also call into question the relevance of the argument that favouring local sectors can boost employment by reducing imports. This is where the two models diverge most. Considering the importance of this subject in political communication, this topic could be the subject of further research. This would require a model with several ${ }_{625}$ countries, able to explain and reproduce the strong divergences of current accounts in the euro area. It would allow to better understand the strength and speed of the adjustment mechanisms, and thus the employment dynamics of reducing imports.

\section{Acknowledgements}

We thank Jean Mercenier, the two anonymous referees of this journal, the anonymous ${ }_{630}$ referee of the FAERE Working Papers series, Frdric Ghersi, Florian Leblanc, Julien Lefvre and Katheline Schubert for their helpful comments on earlier versions. All views expressed here, as well as any errors, are the sole responsibility of the authors. 
Antràs, P., 2004. Is the U.S. Aggregate Production Function Cobb-Douglas? New Estimates of the Elasticity of Substitution. Contributions in Macroeconomics 4, 1-34. doi:10.2202/1534-6005.1161.

635 de Arce, R., Mahía, R., Medina, E., Escribano, G., 2012. A simulation of the economic impact of renewable energy development in Morocco. Energy Policy 46, 335-345. doi:10.1016/j.enpol.2012. 03.068 .

Blanchflower, D.G., Oswald, A.J., 2005. The Wage Curve. NBER Working Paper Series 11338, 493. doi:10.3386/w11338.

640 Böhringer, C., Keller, A., van der Werf, E., 2013. Are green hopes too rosy? Employment and welfare impacts of renewable energy promotion. Energy Economics 36, 277-285. doi:10.1016/j.eneco.2012. 08.029.

Bovenberg, A.L., de Mooij, R.A., 1994. Environmental Levies and Distortionary Taxation. The American Economic Review 84, 1085-1089. doi:10.1016/0176-2680(94)90032-9.

Bovenberg, A.L., Van der Ploeg, F., 1996. Optimal taxation, public goods and environmental policy with involuntary unemployment. Journal of Public Economics 62, 59-83. doi:10.1016/0047-2727 (96) 01574-5.

Cameron, L., van der Zwaan, B., 2015. Employment factors for wind and solar energy technologies: A literature review. Renewable and Sustainable Energy Reviews 45, 160-172. doi:10.1016/j.rser. 2015.01 .001

Chen, Y.H., Paltsev, S., Reilly, J.M., Morris, J.F., Babiker, M.H., 2016. Long-term economic modeling for climate change assessment. Economic Modelling 52, 867-883. doi:10.1016/j.econmod.2015.10.023.

Chiroleu-Assouline, M., 2001. Le double dividende. Les approches théoriques. Revue Française d'Économie 16, 119-147. doi:10.3406/rfeco.2001.1510.

655 Dwyer, L., Forsyth, P., Spurr, R., 2005. Estimating the Impacts of Special Events on an Economy. Journal of Travel Research 43, 351-359. doi:10.1177/0047287505274648.

Fæhn, T., 2015. A shaft of light into the black box of CGE analyses of tax reforms. Economic Modelling 49, 320-330. doi:10.1016/j.econmod.2015.05.003.

Freire-González, J., 2018. Environmental taxation and the double dividend hypothesis in CGE modelling literature: A critical review. Journal of Policy Modeling 40, 194-223. doi:10.1016/J. JPOLMOD . 2017. 11.002 .

Garrett-Peltier, H., 2017. Green versus brown : Comparing the employment impacts of energy efficiency, renewable energy, and fossil fuels using an input-output model. Economic Modelling 61, 439-447. doi:10.1016/j.econmod.2016.11.012.

665 Goulder, L.H., 1994. Environmental taxation and the "double dividend": a reader's guide. NBER Working Paper .

Hartwig, J., Kockat, J., 2016. Macroeconomic effects of energetic building retrofit: input-output sensitivity analyses. Construction Management and Economics 34, 79-97. doi:10.1080/01446193.2016. 1144928.

670 Hillebrand, B., Buttermann, H.G., Behringer, J.M., Bleuel, M., 2006. The expansion of renewable energies and employment effects in Germany. Energy Policy 34, 3484-3494. doi:10.1016/j.enpol 2005.06 .017 .

Hosoe, N., Gasawa, K., Hashimoto, H., 2010. Textbook of Computable General Equilibrium Modeling. Palgrave m ed. doi:10.1057/9780230281653.

675 International Energy Agency, 2013. Transition to Sustainable Buildings: Strategies and Opportunities to 2050. Technical Report. Paris.

International Energy Agency, Nuclear Energy Agency, 2015. Projected costs of generating electricity. Technical Report. OECD. Paris. doi:10.1787/cost_electricity-2015-en.

Kingdon, G.G., Knight, J., 2006. How Flexible Are Wages in Response to Local Unemployment in South Africa? ILR Review 59, 471-495.

Krugman, P., 2012. The Unbearable Slowness of Internal Devaluation. New York Times, Opinion pages: "The conscience of a liberal".

Lehr, U., Lutz, C., Edler, D., O'Sullivan, M., Nienhaus, K., Nitsch, J., Breitschopf, B., Bickel, P. Ottmüller, M., 2012. Green jobs? Economic impacts of renewable energy in Germany. Energy Policy 47, 358-364. doi:10.1016/j.enpol.2012.04.076.

Lehr, U., Nitsch, J., Kratzat, M., Lutz, C., Edler, D., Nitsch, J., Kratzat, M., Lutz, C., Edler, D., 2008. Renewable energy and employment in Germany. Energy Policy 36, 108-117. doi:10.1016/j.enpol. 2007.09 .004

Li, K., Jiang, Z., 2016. The impacts of removing energy subsidies on economy-wide rebound effects in China: An input-output analysis. Energy Policy 98, 62-72. doi:10.1016/j.enpol.2016.08.015.

Markaki, M., Belegri-Roboli, A., Michaelides, P., Mirasgedis, S., Lalas, D.P., 2013. The impact of clean 
energy investments on the Greek economy: An input-output analysis (2010-2020). Energy Policy 57, 263-275. doi:http://dx.doi.org/10.1016/j.enpol.2013.01.047.

O'Hara, J., Pirog, R., 2013. Economic Impacts of Local Food Systems: Future Research Priorities. Journal of Agriculture, Food Systems, and Community Development 3, 1-8. doi:10.5304/jafscd. 2013.034.003.

Partridge, M.D., Rickman, D.S., 1998. Regional computable generale equilibrium modeling: a survey and critical appraisal. International Regional Science Review 21, 205-248.

Patuelli, R., Nijkamp, P., Pels, E., 2005. Environmental tax reform and the double dividend: A metaanalytical performance assessment. Ecological Economics 55, 564-583. doi:10.1016/j.ecolecon. 2004.12.021.

Pearce, D., 1991. The role of carbon taxes in adjusting to global warming. Economic Journal 101, 938-48.

Perrier, Q., Quirion, P., 2017. Is energy transition favourable to sectors with high employment content? An input-output analysis for France. Revue d'économie politique 127.

Pigou, A.C., 1920. The Economics of Welfare. London: Macmillan and Co.

Pollin, R., Garrett-Peltier, H., Heintz, J., Glyn, A., Chakraborty, S., 2015. Global green growth : Clean Energy Industrial Investments and Expanding. Technical Report. United Nations Industrial Development Organization and Global Green Growth Institute. Vienna and Seoul.

710 Sancho, F., 2010. Double dividend effectiveness of energy tax policies and the elasticity of substitution: A CGE appraisal. Energy Policy 38, 2927-2933. doi:10.1016/J.ENPOL.2010.01.028.

Scott, M.J., Roop, J.M., Schultz, R.W., Anderson, D.M., Cort, K.a., 2008. The impact of DOE building technology energy efficiency programs on U.S. employment, income, and investment. Energy Economics 30, 2283-2301. doi:10.1016/j.eneco.2007.09.001.

715 Sen, A., 1963. Neo-Classical and Neo-Keynesian Theories of Distribution. Economic Record 39, 53-64. doi:10.1111/j.1475-4932.1963.tb01459.x.

van der Werf, E., 2008. Production functions for climate policy modeling: An empirical analysis. Energy Economics 30, 2964-2979. doi:10.1016/j.eneco.2008.05.008.

Yushchenko, A., Patel, M.K., 2016. Contributing to a green energy economy? A macroeconomic analysis of an energy efficiency program operated by a Swiss utility. Applied Energy 179, 1304-1320. doi:10 . 1016/j . apenergy . 2015.12.028. 


\section{Appendix A Appendix}

\section{A.1 Getting the Qd matrix}

Value added is equal to output $\boldsymbol{p}$ minus intermediate consumption $\boldsymbol{Z}$. By writing it in an index format, we have :

$$
v a_{j}=p_{j}-\sum_{i} Z_{i, j}=p_{j}-\sum_{i} a_{i, j} \cdot p_{j}=\left(1-\sum_{i} a_{i, j} \cdot p_{j}\right)
$$

So we have:

$$
\tilde{e}=\frac{e t p_{j}}{p_{j}}=\frac{v a_{j}}{p_{j}} \cdot \frac{t e p_{j}}{v a_{j}}=\left(1-\sum_{i} a_{i, j}\right) \cdot e_{j}
$$

which translates in a matrix format into:

$$
\tilde{\boldsymbol{e}}=\boldsymbol{e}^{T r} \cdot\left(\boldsymbol{I}-\boldsymbol{i}^{T} \widehat{r \cdot \boldsymbol{A}^{d}}\right)
$$

\section{A.2 Job creation drivers in input-output analysis}

For a 2 x2 economy, the $\boldsymbol{A}^{\boldsymbol{d}}$ matrix is equal to:

$$
A^{\boldsymbol{d}}=\left(\begin{array}{ll}
\frac{z_{11}}{p_{1}} & \frac{z_{12}}{p_{2}} \\
\frac{z_{21}}{p_{1}} & \frac{z_{22}}{p_{2}}
\end{array}\right)=\left(\begin{array}{ll}
a & b \\
c & d
\end{array}\right)
$$

So:

$$
\begin{gathered}
\boldsymbol{I}-\boldsymbol{A}^{\boldsymbol{d}}=\left(\begin{array}{cc}
1-d & b \\
c & 1-a
\end{array}\right) \\
\left(\boldsymbol{I}-\boldsymbol{A}^{\boldsymbol{d}}\right)^{-1}=\frac{1}{(1-a)(1-d)-b c} \cdot\left(\begin{array}{cc}
1-d & b \\
c & 1-a
\end{array}\right)
\end{gathered}
$$

Following our definition of $\boldsymbol{Q}^{\boldsymbol{d}}=\left(\boldsymbol{I}-\widehat{\boldsymbol{T} \boldsymbol{i} \cdot \boldsymbol{A}^{\boldsymbol{d}}}\right) \cdot\left(\boldsymbol{I}-\boldsymbol{A}^{\boldsymbol{d}}\right)^{-1}$, we get:

$$
\boldsymbol{Q}^{\boldsymbol{d}}=\frac{1}{(1-a)(1-d)-b c} \cdot\left(\begin{array}{cc}
(1-a-c)(1-d) & b(1-a-c) \\
c(1-b-d) & (1-a)(1-b-d)
\end{array}\right)
$$

By noting that the sum of each column is equal to 1 , we can simplify it to

$$
Q^{\boldsymbol{d}}=\left(\begin{array}{cc}
1-\theta_{1} & \theta_{2} \\
\theta_{1} & 1-\theta_{2}
\end{array}\right)
$$

with $\theta_{1}=\frac{(1-b-d) \cdot c}{(1-a)(1-d)-b c}$ and $\theta_{2}=\frac{(1-a-c) \cdot b}{(1-a)(1-d)-b c}$.

This formula illustrates that the Leontief matrix allocates demand between the various sector to generate a value added. For example, an increase of $\delta$ in the demand addressed to sector $\mathrm{S} 1$ would generated a value added in sector $\mathrm{S} 1$ equal to $\left(1-\theta_{1}\right) \cdot \delta$, and a value added in sector $\mathrm{S} 2$ equal to $\theta_{1} \cdot \delta$.

We can now estimate the number of job per unit of final demand. To that end, we define the vector $\tilde{e}$ of job per unit of value added by : $\left(\tilde{e}_{i}\right)=\left(F T E_{i} / V A_{i}\right)$, where $F T E_{i}$ 
is the number of full-time equivalent jobs in sector $i$ and $V A_{i}$ the value added in sector $i$.

The number of jobs per unit of domestic final demand - which we call domestic employment content $c \boldsymbol{e}^{d}-$ is equal to:

$$
{ }^{T} \boldsymbol{c} \boldsymbol{e}^{\boldsymbol{d}}={ }^{T} \tilde{\boldsymbol{e}} \cdot \boldsymbol{Q}=\left(e_{1}\left(1-\theta_{1}\right)+e_{2} \theta_{1} ; \quad e_{1} \theta_{2}+e_{2}\left(1-\theta_{2}\right)\right)
$$

This domestic employment content must now be linked to total final demand. A shift of $\delta$ in final demand from S1 to S2 leads to a change in domestic demand equals to:

$$
\boldsymbol{d}^{\boldsymbol{d}}=<1-\boldsymbol{\tau}_{\boldsymbol{m}}>\cdot\left(\begin{array}{c}
-\delta \\
\delta
\end{array}\right)=\left(\begin{array}{c}
-\left(1-\tau_{1}\right) \\
1-\tau_{2}
\end{array}\right) \cdot \delta
$$

Impacts of shifting investment

An increase of one million euros in final demand addressed to S2 leads to an increase in jobs equal to:

$$
\left(1-\tau_{2}\right) \cdot\left(\left(1-\theta_{2}\right) e_{2}+\theta_{2} e_{1}\right)
$$

An decrease of one million euros in final demand addressed to S1 leads to an increase in jobs equal to:

$$
\left(1-\tau_{1}\right) \cdot\left(\left(1-\theta_{1}\right) e_{1}+\theta_{1} e_{2}\right)
$$

A shift in final demand of one million euros from S1 to S2 leads to an increase in employment if and only if:

$$
\left(1-\tau_{2}\right) \cdot\left(\left(1-\theta_{2}\right) e_{2}+\theta_{2} e_{1}\right)>\left(1-\tau_{1}\right) \cdot\left(\left(1-\theta_{1}\right) e_{1}+\theta_{1} e_{2}\right)
$$

It then useful to note that the right parenthesis in each side is the domestic employment content, a weighted average of direct employment intensity. The above equation can be re-written as:

$$
\left(1-\tau_{2}\right) \cdot c e_{2}^{d}>\left(1-\tau_{1}\right) \cdot c e_{1}^{d}
$$

so a shift in final demand generates jobs if an only if the product of the employment content and the import rate is higher. But the computation of the employment content 740 shows that the domestic employment content is high if demand generates value added in sector with a high number of jobs per value added. 


\section{A.3 Overview of the models used}

Table 7: Overview of model specifications

\begin{tabular}{|c|c|c|c|c|c|}
\hline Model & $\begin{array}{l}\text { Research pur- } \\
\text { pose }\end{array}$ & $\begin{array}{l}\text { Pro- } \\
\text { duction } \\
\text { factors }\end{array}$ & Trade & $\begin{array}{l}\text { Num- } \\
\text { ber of } \\
\text { sec- } \\
\text { tors }\end{array}$ & Description \\
\hline $\begin{array}{l}\text { Closed economy } \\
\text { (A.4) }\end{array}$ & $\begin{array}{l}\text { Labour vs cap- } \\
\text { ital: Targeting } \\
\text { labour-intensive } \\
\text { sectors }\end{array}$ & $\begin{array}{l}\text { capital, } \\
\text { labour }\end{array}$ & NA & 2 & $\begin{array}{l}\text { Sectors differ only } \\
\text { by their capi- } \\
\text { tal/labour ratio }\end{array}$ \\
\hline $\begin{array}{l}\text { Simple CGE } \\
\text { with two labour } \\
\text { skills (A.5) }\end{array}$ & $\begin{array}{l}\text { Encouraging } \\
\text { sectors with low } \\
\text { salaries }\end{array}$ & $\begin{array}{l}\text { capi- } \\
\text { tal, two } \\
\text { labour } \\
\text { skills }\end{array}$ & NA & 2 & $\begin{array}{l}\text { Sectors differ only } \\
\text { by their skills ratio }\end{array}$ \\
\hline $\begin{array}{l}\text { Open economy } \\
(\mathrm{A} .5)\end{array}$ & $\begin{array}{l}\text { The impact of } \\
\text { trade: favour- } \\
\text { ing local pro- } \\
\text { duction? }\end{array}$ & $\begin{array}{l}\text { capital, } \\
\text { labour }\end{array}$ & $\begin{array}{l}\text { small } \\
\text { economy, } \\
\text { Armington, } \\
\text { CET with } \\
\text { infinite } \\
\text { elasticity }\end{array}$ & 2 & $\begin{array}{l}\text { Sectors differ only } \\
\text { by their import } \\
\text { rates }\end{array}$ \\
\hline Full model (A.7) & $\begin{array}{l}\text { Quantification } \\
\text { of two policies: } \\
\text { solar panels and } \\
\text { weatherization }\end{array}$ & $\begin{array}{l}\text { capi- } \\
\text { tal, two } \\
\text { labour } \\
\text { skills }\end{array}$ & $\begin{array}{l}\text { small } \\
\text { economy, } \\
\text { Armington, } \\
\text { CET }\end{array}$ & 58 & $\begin{array}{lr}\text { Full CGE model } \\
\text { with government } \\
\text { spending } \\
\text { taxation }\end{array}$ \\
\hline
\end{tabular}

All these CGE models use wage curves and CES production functions. The model closures are made by assuming fixed current accounts. 
${ }_{745}$ A.4 Closed economy

A.4.1 Overview of the closed model

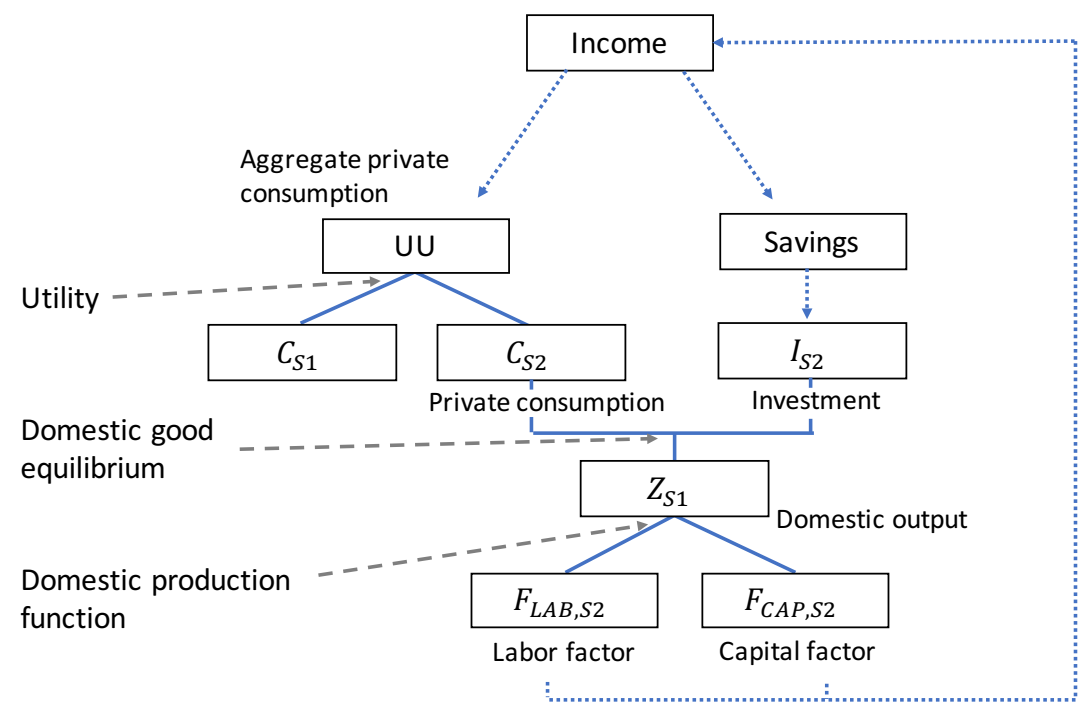

Figure 5: Overview of the closed economy model for the S2 sector

\section{A.4.2 Index of sets}

- $u$ : S1, S2, CAP, LAB, HOH, INV

- $i(u)$ : S1, S2. Alias: $j(u)$.

- $h(u)$ : CAP, LAB.

\section{A.4.3 Index of variables}

- $Z_{j}$ : output of the j-th good

- $F_{h, j}$ : the h-th factor input by the j-th firm

- $F F_{h}$ : the h-th factor supply

- Inc: Household income

- $C_{i}$ : household consumption of the i-th good

- $p_{i}^{x}$ : demand price of the i-th good

- $p_{i}^{z}$ supply price of the i-th good

- $p_{h}^{f}$ the h-th factor price 
- $S^{p}$ : private savings

- $U$ : unemployment rate

- $U U$ : utility (Cobb-Douglas)

\section{A.4.4 Index of parameters}

765

- $\alpha_{i}$ : share parameter in utility function

- $\sigma^{z}$ : elasticity in CES production function

- $\rho^{z}=\frac{\sigma^{z}-1}{\sigma^{z}}$ : param. in CES production function

- $\delta_{h, j}$ share parameter in CES production function

- $s c Z_{j}$ : scale parameter in CES production function

770

- $\beta_{h, j}$ : share parameter in Cobb-Douglas production function

- $b_{j}$ : scale parameter in Cobb-Douglas production function

- $a_{h, j}$ : Leontief coefficient in production function

- $\gamma$ : wage curve elasticity

- $U^{0}$ : initial unemployment rate

\section{A.4.5 Tests}

Walras' law Walras' law allows to take off one equation. In our numerical application, we remove the market clearing of good for the first sector. Then, we check after the run that Walras' law is satisfied.

Numraire In our numerical application, we use the price index of consumption goods as the numraire. We check that the model is not sensitive to this assumption. We increase the numraire by $10 \%$ and rerun the model. With this assumption, we check that all prices have increased by $10 \%$, and volumes remain the same. 
Table 8: Comparative equations of IO and CGE models.

\begin{tabular}{llll}
\hline Num & Description & CGE 1 & IO model \\
\hline eq1 & Production function & $Z_{j}=s c Z_{j} \cdot\left(\sum_{h} \delta_{h, j} F_{h, j}^{\rho^{z}}\right)^{1 / \rho^{z}}$ & $Z_{j}=\min _{h}\left(\frac{F_{h, j}}{a_{h, j}}\right)$ \\
eq2 & Factor demand (K and L) & $F_{h, j}=\left(s c Z_{j}^{\rho^{z}} \delta_{h, j} p_{j}^{z} / p_{h}^{f}\right)^{\sigma^{z}} Z_{j}$ & $F_{h, j}=a_{h, j} \cdot Z_{j}$ \\
eq3 & Household demand & $C_{i}=\frac{\alpha_{i}}{p_{i}^{c}}\left(\operatorname{Inc}-S^{p}\right)$ & $C_{i}=\overline{C_{i}}$ \\
eq4 & Labour supply & $\log \left(\frac{p_{L A B}^{f}}{p c}\right)=-\gamma \cdot \log \left(\frac{U}{U^{0}}\right)$ & $p_{\text {Lab }}^{f}=1$ \\
eq5 & Capital supply & $F F_{C A P}=\overline{F F} F_{C A P}$ & $p_{C a p}^{f}=1$ \\
eq6 & Unemployment & $U=1-F F_{L A B} / P o p$ & $i d e m$ \\
eq7 & Household income & $I n c=\sum_{h} p_{h}^{f} \cdot F F_{h}$ & idem \\
eq8 & Investment & $I_{i}=\overline{I_{i}}$ & idem \\
eq9 & Savings & $S^{p}=\sum_{i} p_{i}^{c} \cdot I_{i}$ & $i d e m$ \\
eq10 & Balance of domestic good & $Z_{i}=C_{i}+I_{i}$ & $i d e m$ \\
eq11 & Balance of factors & $F F_{h}=\sum_{j} F_{h, j}$ & $i d e m$ \\
eq12 & Price equality & $p_{i}^{c}=p_{i}^{z}$ & idem \\
eq13 & Consumption price index & $p^{c}=\prod_{i}\left(p_{i}^{c}\right)^{\alpha_{i}}$ & idem \\
\hline
\end{tabular}

$i d e m$ indicates that the equation in this row is identical for the two models. More information on this model can be found in appendix, section A.4.

When the capital-labour elasticity tends to zero and one, we get the limiting cases of the Leontief and Cobb-Douglas function. In such cases, to avoid issues with zeros, we replace the production function with a zero profit condition for the Leontief case, $p_{j}^{z}=\sum_{h} p_{h}^{f} \cdot a_{h, j}^{z}$, and for the Cobb-Douglas with the function: $Z_{j}=b_{j} \cdot \prod_{h} F_{h, j}^{\beta_{h, j}}$.

The respective factor demand functions are $F_{h, j}=a_{h, j}^{z} \cdot Z_{j}$ and $F_{h, j}=\beta_{h, j} \cdot p_{j}^{z} \cdot Z_{j} / p_{h}^{f}$. 


\section{A.5 Simple CGE with two labour skills}

A.5.1 Overview of the simple CGE with two labour skills

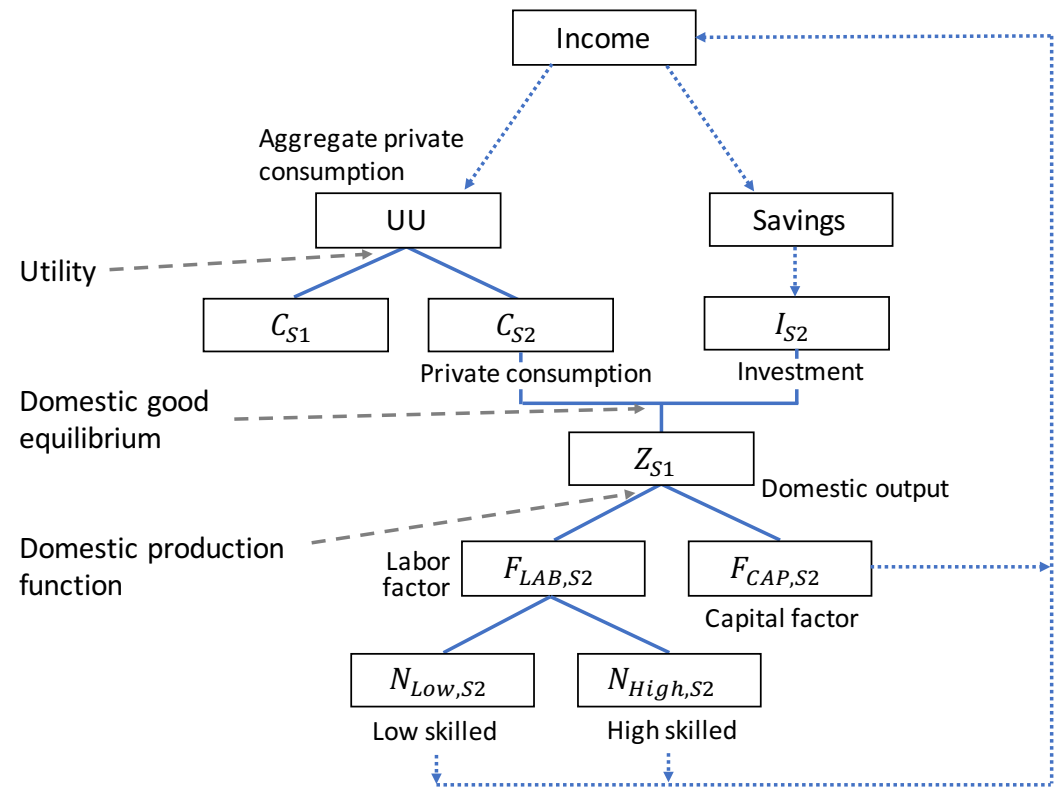

Figure 6: Overview of the open economy model for the S2 sector

785

\section{A.5.2 Index of sets}

- $u$ : S1, S2, CAP, LAB, HOH, INV

- $i(u)$ : S1, S2. Alias: $j(u)$

- $h(u)$ : CAP, LAB

- $s$ : LABL, LABH 


\begin{tabular}{lllllll}
\hline & S1 & S2 & LAB & CAP & HOH & INV \\
\hline S1 & & & & & 9 & 5 \\
S2 & & & & & 9 & 5 \\
LAB & 9 & 9 & & & & \\
CAP & 5 & 5 & & & & \\
HOH & & & 18 & 10 & & \\
INV & & & & & 10 & \\
\hline
\end{tabular}

Table 9: A 2x2 economy with wage differences

\begin{tabular}{lll}
\hline & S1 & S2 \\
\hline Low-skilled & 7 & 3 \\
High-skilled & 1 & 3 \\
\hline
\end{tabular}

Table 10: Initial number of workers by skill in each sector 


\section{A.6 Open economy}

\section{A.6.1 Overview of the open economy}

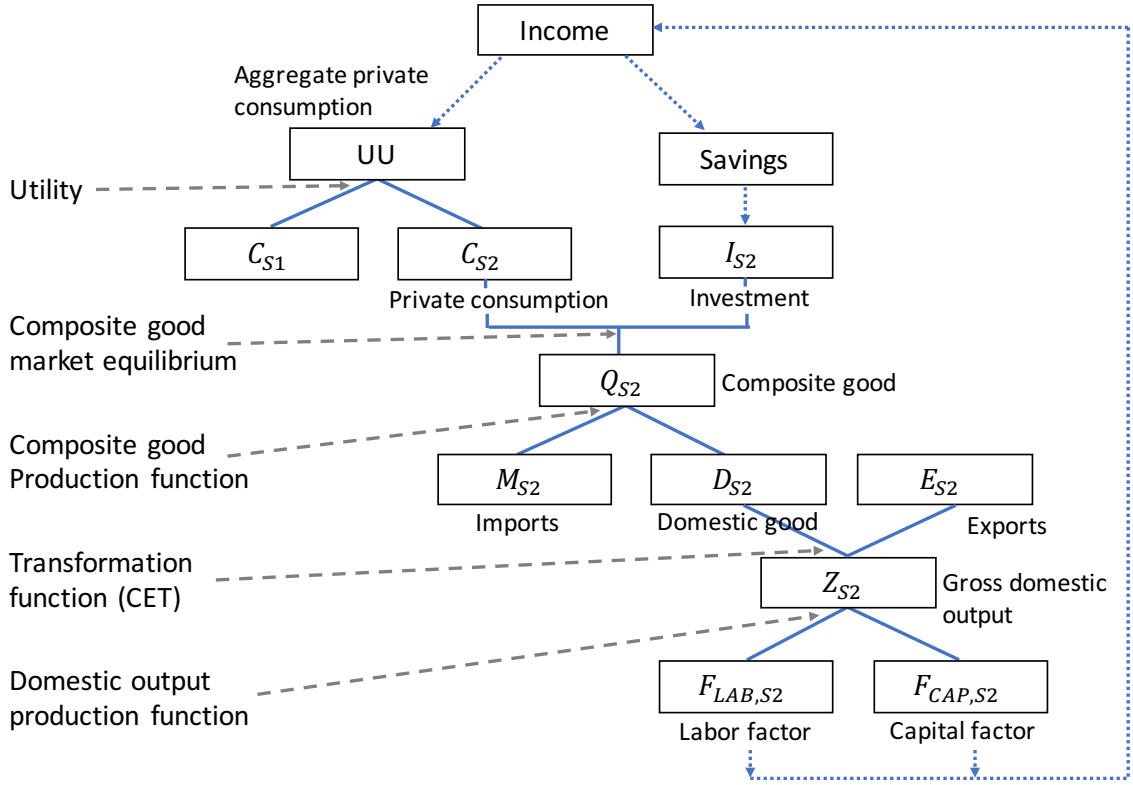

Figure 7: Overview of the open economy model for the S2 sector

\section{A.6.2 Index of sets}

- $u$ : S1, S2, CAP, LAB, HOH, INV, EXT

- $i(u): \mathrm{S} 1, \mathrm{~S} 2$

- $h(u)$ : CAP, LAB

\section{A.6.3 Index of variables}

- $Z_{j}$ : output of the j-th good

- $F F_{h}$ : factor supply

- $F_{h, j}$ : the h-th factor input by the j-th firm

- Inc: Household income

- $C_{i}$ : household consumption of the i-th good

- $E_{i}$ : exports

- $M_{i}$ : imports 


\begin{tabular}{|c|c|c|c|}
\hline Num & Description & Standard CGE 2 & IO model \\
\hline eq1 & Production function & $Z_{j}=s c Z_{j} \cdot\left(\sum_{h} \delta_{h, j} F_{h, j}^{\rho^{z}}\right)^{1 / \rho^{z}}$ & $Z_{j}=\min _{h}\left(\frac{\left.F_{h, j}\right)}{a_{h, j}}\right)$ \\
\hline eq2 & Factor demand & $F_{h, j}=\left(s c Z_{j}^{\rho^{z}} \cdot \delta_{h, j} \cdot p_{j}^{z} / p_{h}^{f}\right)^{\sigma^{z}} Z_{j}$ & $F_{h, j}=a_{h, j} Z_{j}$ \\
\hline eq3 & Household income & $I n c=\sum_{h} p_{h}^{f} \cdot F F_{h}$ & idem \\
\hline eq4 & Household demand & $C_{i}=\frac{\alpha^{U}}{v^{x}}\left(\operatorname{Inc}-S^{p}\right)$ & $C_{i}=\overline{C_{i}}$ \\
\hline eq5 & Unemployment & $U=1-F F_{L A B} / P o p$ & idem \\
\hline eq6 & Labour supply & $\log \left(\frac{p_{L A B}^{f}}{p c}\right)=-\gamma \log \left(U / U^{0}\right)$ & $p_{L a b}^{f}=1$ \\
\hline eq7 & Capital supply & $F F_{C A P}=\overline{F F_{C A P}}$ & $p_{C A P}^{f}=1$ \\
\hline eq8 & Investment & $I=\bar{I}$ & idem \\
\hline eq9 & Private savings & $S^{p}=\sum_{i} p_{i}^{x} I_{i}-\epsilon \cdot S^{f}$ & idem \\
\hline eq10 & Trade closure & $S^{f}=\overline{\overline{S^{f}}}$ & \\
\hline eq11 & Balance for domestic good & $Q_{i}=C_{i}+I_{i}$ & idem \\
\hline eq12 & Balance for factors & $F F_{h}=\sum_{j} F_{h, j}$ & idem \\
\hline eq13 & Price equality & $p_{i}^{x}=p_{i}^{q}$ & idem \\
\hline eq14 & Consumption price index & $p^{c}=\prod_{i}\left(p_{i}^{x}\right)^{\alpha_{i}^{u}}$ & idem \\
\hline eq15 & Export demand & $p_{i}^{e}=\epsilon \cdot p_{i}^{W e}$ & $E_{i}=\overline{E_{i}}$ \\
\hline eq16 & Import supply & $p_{i}^{m}=\epsilon \cdot \overline{p_{i}^{W m}}$ & idem \\
\hline eq17 & Trade balance & $\sum_{i} \overline{p_{i}^{W e}} E_{i}+S^{f}=\sum_{i} \overline{p_{i}^{W m}} M_{i}$ & idem \\
\hline eq18 & Armington function & $Q_{i}=s c Q_{i}\left(\alpha_{i}^{m} M_{i}^{\rho_{Q}}+\alpha_{i}^{d} D_{i}^{\rho_{Q}}\right)^{1 / \rho_{Q}}$ & $\begin{array}{l}p_{i}^{Q} Q_{i}+p_{i}^{e} E_{i} \\
=p_{i}^{m} M_{i}+p_{i}^{d} D_{i}\end{array}$ \\
\hline eq19 & Imports demand & $M_{i}=\left(s c Q_{i}^{\rho_{Q}} \cdot \alpha_{i}^{m} \cdot \frac{p_{i}^{Q}}{p_{i}^{m}}\right)^{\sigma_{Q}} Q_{i}$ & $M_{i}=\lambda_{i}^{m}\left(Q_{i}+E_{i}\right)$ \\
\hline eq20 & Domestic demand & $D_{i}=\left(s c Q_{i}^{\rho_{Q}} \cdot \alpha_{i}^{d} \cdot \frac{p_{i}^{Q}}{p^{d}}\right)^{\sigma_{Q}} Q_{i}$ & $Z_{i}=\lambda_{i}^{z}\left(Q_{i}+E_{i}\right)$ \\
\hline eq21 & CET function & $Z_{i}=\theta_{i} \cdot\left(\xi_{i}^{e} \cdot E_{i}^{\phi_{i}}+\xi_{i}^{d} \cdot D_{i}^{\phi_{i}}\right)^{\left(1 / \phi_{i}\right)}$ & idem \\
\hline eq22 & Supply of E & $E_{i}=\left(\theta_{i}^{\phi_{i}} \cdot \xi_{i}^{e} \cdot\left(1+\tau_{i}^{z}\right) p_{i}^{z} / p_{i}^{e}\right)^{\left(1 /\left(1-\phi_{i}\right)\right)} Z_{i}$ & idem \\
\hline eq23 & Supply of D & $D_{i}=\left(\theta_{i}^{\phi_{i}} \cdot \xi_{i}^{d} \cdot\left(1+\tau_{i}^{z}\right) p_{i}^{z} / p_{i}^{d}\right)^{\left(1 /\left(1-\phi_{i}\right)\right)} Z_{i}$ & idem \\
\hline
\end{tabular}

Table 11: Comparative equations of IO and CGE models. Identical equations are not repeated to facilitate reading. The main differences with the closed version shown in table 8 have their equations labelled in bold.

- $Q_{i}$ : Armington composite good

- $D_{i}$ : domestic good

- $p f_{h}$ : the h-th factor price

- $p_{i}^{x}$ : consumption price

- $p_{j}^{z}$ : supply price of the i-th good

- $p_{i}^{q}$ : Armington composite good price

- $p_{i}^{e}$ : export price in local currency

- $p_{i}^{m}$ : import price in local currency

- $p_{i}^{d}$ : the i-th domestic good price 
- $\epsilon$ : exchange rate

- $p^{c}$ : price index

- $S^{p}$ : private savings

- $S^{f}$ : foreign savings

- $U$ : unemployment rate

- $U U$ : utility (Cobb-Douglas)

$820 \quad$ A.6.4 Index of parameters

- $\alpha_{i}^{u}$ : share parameter in utility func.

- $\sigma^{z}$ : elasticity in CES production function

- $\rho^{z}=\frac{\sigma^{z}-1}{\sigma^{z}}$ : param. in CES production function

- $\delta_{h, j}$ share parameter in CES production function

825

- $s c Z_{j}$ : scale parameter in CES production function

- $\sigma^{q}$ : elasticity of Armington substitution

- $\rho^{q}=\frac{\sigma^{q}-1}{\sigma^{q}}$ : substitution elasticity parameter for Armington

- $\alpha_{i}^{m}$ : share par. in Armington func.

- $\alpha_{i}^{d}$ : share par. in Armington func.

830

- $s c q_{i}$ : scale par. in Armington func.

- $\gamma$ : wage curve elasticity

- $U^{0}$ : initial unemployment rate 


\section{A.6.5 Results for IO and CGE}

\begin{tabular}{l|lllllll}
\hline & S1 & S2 & LAB & CAP & HOH & INV & EXP \\
\hline S1 & & & & & 8 & 4 & 3 \\
S2 & & & & & 12 & 4 & 3 \\
LAB & 9 & 9 & & & & & \\
CAP & 5 & 5 & & & & & \\
HOH & & & 18 & 10 & & & \\
INV & & & & & 8 & & \\
IMP & 1 & 5 & & & & & \\
\hline
\end{tabular}

Table 12: Initial SAM of the open economy

\begin{tabular}{l|lllll}
\hline & S1 & S2 & HOH & INV & EXP \\
\hline S1 & & & 8 & 5 & 3 \\
S2 & & & 12 & 3 & 3 \\
LAB & 9.60 & 8.53 & & & \\
CAP & 5.33 & 4.74 & & & \\
IMP & 1.07 & 4.74 & & & \\
\hline
\end{tabular}

Table 13: IO results in an open economy

\begin{tabular}{l|lllll}
\hline & S1 & S2 & HOH & INV & EXT \\
\hline S1 & & & 8.00 & 5.00 & 3.12 \\
S2 & & & 12.00 & 3.00 & 2.69 \\
LAB & 9.66 & 8.34 & & & \\
CAP & 5.37 & 4.63 & & & \\
EXT & 1.09 & 4.72 & & & \\
\hline
\end{tabular}

Table 14: CGE results in an open economy with fixed foreign savings 


\section{A.6.6 Results for IO and CGE with low exports and low imports}

\begin{tabular}{l|lllll}
\hline Sector & S1 & S2 & HOH & INV & EXP \\
\hline S1 & & & 9 & 4 & 0 \\
S2 & & & 13 & 4 & 0 \\
LAB & 8 & 8 & & & \\
CAP & 4 & 4 & & & \\
IMP & 1 & 5 & & & \\
\hline
\end{tabular}

Table 15: SAM of an economy with low imports and low exports in S1, before investment shock

\begin{tabular}{l|lllll}
\hline & S1 & S2 & HOH & INV & EXP \\
\hline S1 & & & 9 & 5 & 0 \\
S2 & & & 13.02 & 3 & 0 \\
LAB & 8.58 & 7.44 & & & \\
CAP & 4.29 & 3.71 & & & \\
IMP & 1.13 & 4.87 & & & \\
\hline
\end{tabular}

Table 16: SAM of an economy with low imports and low exports in S1, after investment shock 


\section{A.7 Full model}

\section{A.7.1 Data}

At the 64-sector level of disaggregation, we encounter some issues to calibrate the CGE model:

- Postal services (CPA_H53) have negative capital revenues in 2013. Standard production functions with constant elasticity of substitution cannot account for a negative capital revenue. Since this sector is not crucial for our analysis of green jobs, we aggregate it with the other transportation service (CPA_H50, CPA_H51 and CPA_H52).

- The "Manufacture of textiles, wearing apparel and leather products" sector (CPA_C13-15) and "Computer, electronic and optical products" sector (CPA_C26) export more than they produce. To avoid issues with negative values in the calibration of trade within the constant elasticity of transformation (CET) function, we aggregate the textile and leather products with "Manufacture of wood and of products of wood" (CPA_C16) and computers with electrical equipment (CPA_C27)

- The "imputed rent" sector (CPA_L68A) indicates a low but positive remuneration for employees, but no employee. This would lead to an infinite salary. We aggregate this sector with the other real estate services (CPA_L68B)

\section{A.7.2 Overview of the full CGE model}

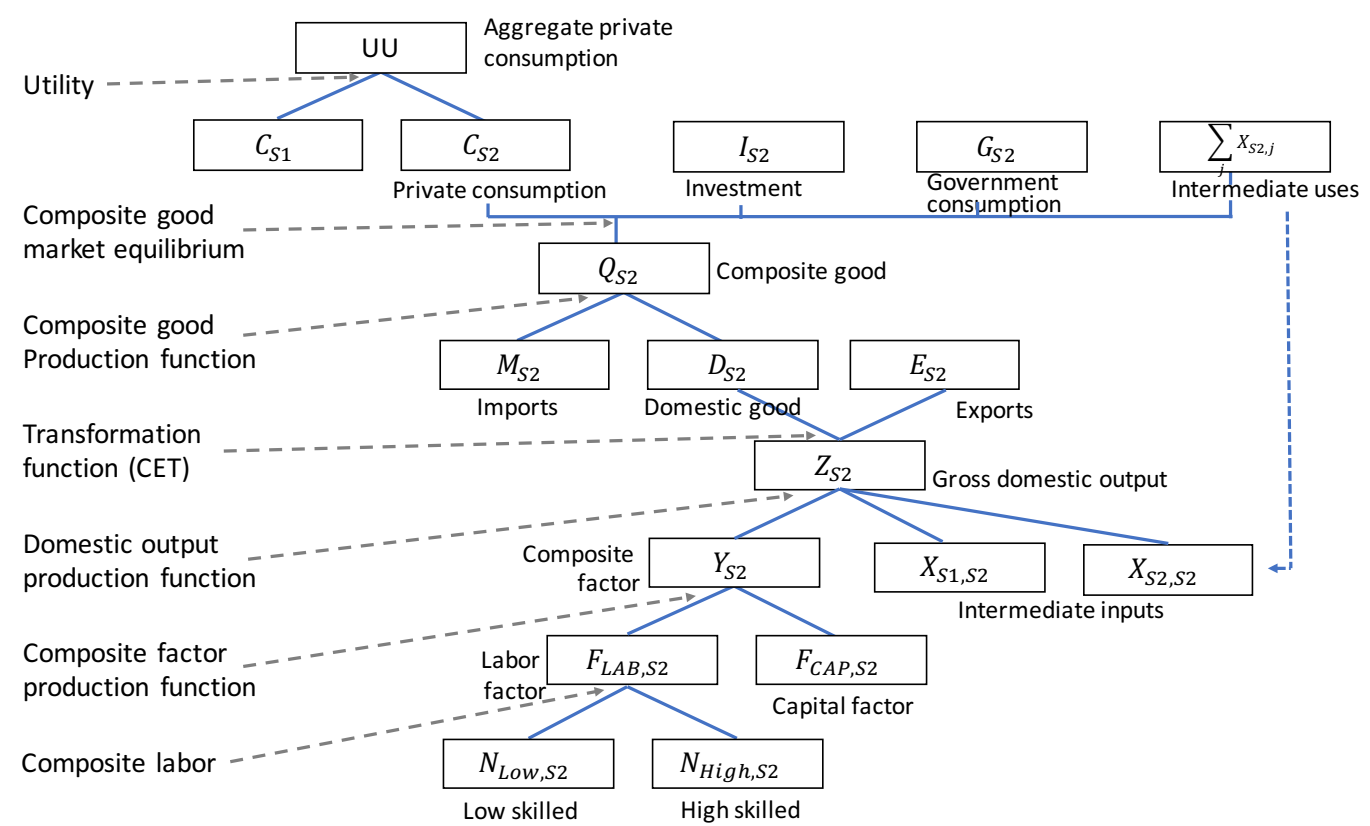

Figure 8: Overview of the fully-fledged model for the S2 sector 


\section{A.7.3 Index of sets}

855

- u: SAM entry /S1*S58, CAP, LAB, IDT, TRF, HOH, GOV,

- $\mathrm{i}(\mathrm{u})$ : goods $/ \mathrm{S} 1 * \mathrm{~S} 58 /$

- $\mathrm{h}(\mathrm{u})$ : factor /CAP, LAB/

- s: labour skill / highSkill, lowSkill /

\section{A.7.4 Index of variables}

860

- $Y_{j}$ : composite factor

- Inc: household income

- $N(s, j)$ : worker input by skill

- $K_{j}$ : capital factor input by the $\mathrm{j}$-th firm

- $L_{j}$ : labour input

865

- $K K$ : capital supply

- $N N(s)$ : worker supply

- $X(i, j)$ : intermediate input

- $Z_{j}$ : output of the $\mathrm{j}$-th good

- $C_{i}$ : household consumption of the i-th good

870

- $G_{i}$ : government consumption

- $I_{i}$ : investment

- $E_{i}$ : exports

- $M_{i}$ : imports

- $Q_{i}$ : Armington composite good

875 - $D_{i}$ : domestic good

- $p^{k}$ : capital factor price

- $p_{j}^{l}$ : labour price

- $p_{s}^{n}$ : workers price

- $p_{j}^{y}$ : composite factor price

${ }_{880}-p_{j}^{z}$ : supply price of the i-th good

- $p_{i}^{q}$ : Armington composite good price 
- $p_{i}^{e}$ : export price in local currency

- $p_{i}^{m}$ : import price in local currency

- $p_{i}^{d}$ : the i-th domestic good price

- $\epsilon$ : exchange rate

- $S^{p}$ : private saving

- $S^{g}$ : government saving

- $S^{f}$ : foreign saving

- $T^{d}$ : direct tax

- $T_{j}^{z}$ : production tax

- $T^{p}$ : private consumption tax

- $T^{v}$ : investment tax

- $K K$ : capital supply

- $N N_{s}$ : labour supply

- $p c$ : consumption price

- $U U$ : utility (Cobb-Douglas)

\section{A.7.5 Index of parameters}

- $\sigma^{Y}$ : elasticity of substitution in composite factor production

- $\rho^{Y}=\frac{\sigma^{Y}-1}{\sigma^{Y}}$ : substitution elasticity parameter for capital-labour composite

- $\sigma_{i}$ : elasticity of Armington substitution

- $\eta_{i}=\frac{\sigma^{z}-1}{\sigma^{z}}$ : substitution elasticity parameter for Armington

- $\psi_{i}$ : elasticity of transformation

- $\phi_{i}=\frac{\psi^{z}-1}{\psi^{z}}$ : transformation elasticity parameter

- $\alpha_{i}$ : share parameter in utility func.

- $\delta_{j}^{l}$ : labour share in CES prod. func.

- $\delta_{j}^{k}$ : capital share in CES prod. func.

- $s c Y$ : scale param. in CES prod. func.

- $\beta_{-} N(s, j)$ : share parameter in labour function

- $s c L_{j}$ : scale parameter in labour function 
- $a x(i, j)$ : intermediate input requirement coeff.

- $a y_{j}$ : composite fact. input req. coeff.

- $\mu_{i}$ : government consumption share

- $\lambda_{i}$ : investment demand share

- $\delta_{i}^{m}$ : share par. in Armington func.

- $\delta_{i}^{d}$ : share par. in Armington func.

- $s c Q_{i}$ : scale par. in Armington func.

- $\xi_{i}^{d}$ : share par. in transformation func.

- $\xi_{i}^{e}$ : share par. in transformation func.

- $\theta_{i}$ : scale par. in transformation func.

- ssg: average propensity for gov. saving

- $\tau^{d}$ : direct tax rate

- Pop: population (labour force)

- $U_{s}^{0}$ : initial unemployment

- $p_{i}^{W e}$ : export price in US dollars

- $p_{i}^{W m}$ : import price in US dollars

- $\tau_{i}^{z}$ : production tax rate

- $\tau^{p}$ : private consumption tax rate

- $\tau^{v}$ : investment tax

- Pop: population (labour force)

- $\gamma$ : wage curve elasticity 
Table 17: Comparative equations of IO and CGE models. Identical equations are not repeated to facilitate reading. The main differences with the closed version shown in table 8 have their equations labelled in bold.

\begin{tabular}{|c|c|c|}
\hline Num & Description & CGE \\
\hline eq1 & Production function & $Y_{j}=s c Y_{j} \cdot\left(\delta_{j}^{k} \cdot K_{j}^{\rho_{Y}}+\delta_{j}^{l} \cdot L_{j}^{\rho_{Y}}\right)^{1 / \rho_{Y}}$ \\
\hline eq2 & Capital demand & $K_{j}=\left(s c Y_{j}^{\rho_{Y}} \cdot \delta_{j}^{k} \cdot p_{j}^{y} / p^{k}\right)^{\sigma_{Y}} \cdot Y_{j}$ \\
\hline eq3 & Labour demand & $L_{j}=\left(s c Y_{j}^{\rho_{Y}} \cdot \delta_{j}^{l} \cdot p_{j}^{y} / p_{j}^{l}\right)^{\sigma_{Y}} \cdot Y_{j}$ \\
\hline eq4 & Demand of intermediate goods & $X_{i, j}=a x_{i, j} \cdot Z_{j}$ \\
\hline eq5 & Demand of composite factor & $Y_{j}=a y_{j} \cdot Z_{j}$ \\
\hline eq6 & Condition of zero profit & $p_{j}^{z}=a y_{j} \cdot p_{j}^{y}+\sum_{i} a x_{i, j} \cdot p_{i}^{q}$ \\
\hline eq7 & Production of labour composite & $L_{j}=s c L_{j} \cdot \prod_{s} N_{s, j}^{\beta_{s, j}^{N}}$ \\
\hline eq8 & Demand of labour by skill & $N_{s, j}=\beta_{s, j}^{N} \cdot p_{j}^{l} \cdot L_{j} / p_{s}^{n}$ \\
\hline eq9 & Unemployment & $U_{s}=1-N N_{s} / \operatorname{Pop}_{s}$ \\
\hline eq10 & Labour supply & $\log \left(p_{s}^{n} / p^{c}\right)=-\gamma \cdot \log \left(\frac{U_{s}}{U^{0}}\right)$ \\
\hline eq11 & Capital supply & $K K=\overline{K K}$ \\
\hline eq12 & Direct tax on household & $T^{d}=\tau^{d} \cdot \operatorname{Inc}$ \\
\hline eq13 & Tax on production & $T_{j}^{z}=\tau_{j}^{z} \cdot p_{j}^{z} \cdot Z_{j}$ \\
\hline eq14 & Tax on household consumption & $T^{p}=\tau^{p} \cdot \sum_{j} p_{j}^{q} \cdot C_{j}$ \\
\hline eq15 & Tax on investment & $T^{v}=\tau^{v} \cdot \sum_{j} p_{j}^{q} \cdot I_{j}$ \\
\hline eq16 & Government income & Gov_inc $=T^{d}+\sum_{j} T_{j}^{z}+T^{p}+T^{v}$ \\
\hline eq16 & Government consumption & $\sum_{i} p_{i}^{q} \cdot\left(1+\tau^{g}\right) \cdot G_{i}=(1-s s g) \cdot G o v \_i n c$ \\
\hline eq18 & Government savings & $S^{g}=s s g \cdot G o v \_i n c$ \\
\hline eq19 & Household income & $I n c=p^{k} \cdot K K+\sum_{s} p_{s}^{n} \cdot N N_{s}$ \\
\hline eq20 & Houshold consumption & $C_{i}=\alpha_{i} \cdot\left(\operatorname{Inc}-S^{p}-T^{d}\right) /\left(\left(1+\tau^{p}\right) p_{i}^{q}\right)$ \\
\hline eq17 & Private savings & $S^{p}=\sum_{i}\left(1+\tau^{v}\right) \cdot p_{i}^{q} \cdot I_{i}-S^{g}-\epsilon \cdot S^{f}$ \\
\hline eq21 & Export demand & $p_{i}^{e}=\epsilon \cdot p W e_{i}$ \\
\hline eq22 & Import supply & $p_{i}^{m}=\epsilon \cdot p_{i}^{W m}$ \\
\hline eq23 & Balance of trade & $\sum_{i} p_{i}^{W e} \cdot E_{i}+S^{f}=\sum_{i} p_{i}^{W m} \cdot M_{i}$ \\
\hline eq24 & Trade closure & $S^{f}=\overline{S^{f}}$ \\
\hline eq25 & Armington function & $Q_{i}=s c Q_{i} \cdot\left(\alpha_{i}^{m} M_{i}^{\rho_{Q}}+\alpha_{i}^{d} D_{i}^{\rho_{Q}}\right)^{1 / \rho_{Q}}$ \\
\hline eq26 & Imports demand & $M_{i}=\left(s c Q_{i}^{\rho_{Q}} \cdot \alpha_{i}^{m} \cdot \frac{p_{i}^{q}}{p_{i}^{m}}\right)^{\sigma_{Q}} Q_{i}$ \\
\hline eq27 & Domestic demand & $D_{i}=\left(s c Q_{i}^{\rho_{Q}} \cdot \alpha_{i}^{d} \cdot \frac{p_{i}^{q}}{p_{i}^{d}}\right)^{\sigma_{Q}} Q_{i}$ \\
\hline eq28 & CET function & $Z_{i}=\theta_{i} \cdot\left(\xi_{i}^{e} \cdot E_{i}^{\phi_{i}}+\xi_{i}^{d} \cdot D_{i}^{\phi_{i}}\right)^{\left(1 / \phi_{i}\right)}$ \\
\hline eq29 & Demand of E & $E_{i}=\left(\theta_{i}^{\phi_{i}} \cdot \xi_{i}^{e} \cdot\left(1+\tau_{i}^{z}\right) p_{i}^{z} / p_{i}^{e}\right)^{\left(1 /\left(1-\phi_{i}\right)\right)} Z_{i}$ \\
\hline eq30 & Demand of D & $D_{i}=\left(\theta_{i}^{\phi_{i}} \cdot \xi_{i}^{d} \cdot\left(1+\tau_{i}^{z}\right) p_{i}^{z} / p_{i}^{d}\right)^{\left(1 /\left(1-\phi_{i}\right)\right)} Z_{i}$ \\
\hline eq31 & Balance of domestic good & $Q_{i}=C_{i}+I_{i}+G_{i}+\sum_{j} X_{i, j}$ \\
\hline eq32 & Balance of labour & $N N_{s}=\sum_{j} N_{s, j}$ \\
\hline eq33 & Balance of capital & $K K=\sum_{j} K_{j}$ \\
\hline eq34 & Price equality & $p_{i}^{c}=\prod_{i}\left(1+\tau_{p}\right) \cdot\left(p_{i}^{q}\right)^{\alpha_{i}}$ \\
\hline
\end{tabular}




\section{A.7.6 Cobb-Douglas elasticity vs Empirical estimates}

Table 18: Comparing job creation using CES vs Cobb-Douglas

(for a wage curve elasticity of 0.1 , Armington and CET elasticities of 2

\begin{tabular}{lcccc}
\hline Technology & $\begin{array}{c}\text { Elasticity } \\
\sigma_{K L}\end{array}$ & $\begin{array}{c}\text { Value } \\
\text { with CES }\end{array}$ & $\begin{array}{c}\text { Value } \\
\text { with Cobb-Douglas }\end{array}$ & $\begin{array}{c}\text { Difference (\%) } \\
\text { Cobb-Douglas vs CES }\end{array}$ \\
\hline Solar & 0.2 & 5858 & 3542 & -40 \\
Solar & 0.3 & 5394 & 3542 & -34 \\
Solar & 0.4 & 5003 & 3542 & -29 \\
Solar & 0.5 & 4670 & 3542 & -24 \\
Solar & 0.6 & 4382 & 3542 & -19 \\
Weatherization & 0.2 & 6589 & 4135 & -37 \\
Weatherization & 0.3 & 6097 & 4135 & -32 \\
Weatherization & 0.4 & 5683 & 4135 & -27 \\
Weatherization & 0.5 & 5331 & 4135 & -22 \\
Weatherization & 0.6 & 5026 & 4135 & -18 \\
\hline
\end{tabular}

\section{A.7.7 Trade}

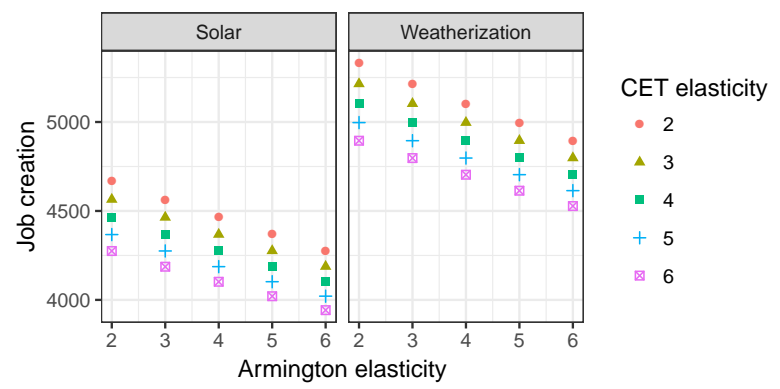

Figure 9: Sensitivity of job impacts to Armington and CET elasticities 